\title{
Razón y amor en la Teológica de Hans Urs von Balthasar
}

La antiquísima pregunta por la relación entre razón y amor recibe una respuesta novedosa, sin duda, en la obra de Hans Urs von Balthasar (1). Sin embargo, resulta extremadamente difícil precisar esta respuesta con debido rigor científico, ya que involucra toda la voluminosa obra del teólogo suizo tanto en su estructura externa como su gestación interna (2). En efecto, el estudio de la extensa obra de Balthasar no deja ningún lugar a dudas respecto de la relevancia del amor como principio articulador de su pensamiento, constituyéndose en trascendental por excelencia en interrelación con los trascendentales del ser (3).

Los numerosos estudios secundarios que, de modo penetrante y asertivo, abordan el problema razón y amor en la obra balthasariana, adolecen de defectos congénitos, ya que recién a partir de 1987 se posee la visión completa de la obra del teólogo suizo (4). Por cierto, con la entrega de la Teológica,"el último regalo", es posible un estudio completo de la relación razón y amor en dicha obra (5). A partir de este momento, la atención de los críticos, centrada más bien en el fenómeno del

(1) BALTHASAR H. U., Solo el amor es Signo de fe, Salamanca 1995, 12: “...Quienes más aman a Dios son los que más saben de Él, y, por tanto, es preciso prestarles atención”; KERN U., Liebe als Erkenntnis und Konstruktion von Wirklichkeit. "Erinnerung" an ein stets aktuales Erkenntnispotential (Theologische Bibliothek Töpelmann, 109) Berlin-New York 2001, 295 pp. Cf. MEIS A., El significado teológico de la frase "El conocimiento se convierte en amor" (De an et res, PG 46, 96.37) de Gregorio de Nisa y su recepción por Guillermo de Saint Thierry, Teología y Vida 43 (2002) 285-302; ídem, Razón y amor en la Teología Medieval, Teología y Vida 43 (2002) 540-578.

(2) Cf. LOCHBRUNNER M., Hans Urs von Balthasar Trilogie der Liebe, FKT 11(1995) 161-181; KIM S.-T., Christliche Denkform: Theozentrik oder Anthropozentrik? Die Frage nach dem Subjekt der Geschichte bei Hans Urs von Balthasar und Johann Baptist Metz, Freiburg Schweiz 1999,143-146, 156-164.

(3) BALTHASAR H. U., Epilog, Einsiedeln 1987; Cf. DISSE J., Liebe und Erkenntnis, Zur Geistmetaphysik Hans Urs von Balthasars, MThZ (1999) 19-227; O'DONNEL J., Alles Sein ist Liebe. Eine Skizze der Theologie Hans Urs von Balthasars, en LEHMANN K., KASPER W. (eds), Hans Urs von Balthasar. Gestalt und Werk.Köln 1989, 260-276. Conserva su vigencia la entrevista ALBUS M., Geist und Feuer.Ein Gespräch mit Hans Urs von Balthasar, HerKorr 1976, 72-82.

(4) Cf. BALTHASAR H. U., Mein Werk. Durchblicke, Einsiedeln 1990, $111 \mathrm{pp.}$

(5) PLAGA U. J., "Ich bin die Wahrheit". Die theo-logische Dimension der Christologie Hans Urs von Balthasars (Theologie, 12) Bochum 1997, $471 \mathrm{pp}$. 
amor, se comienza a desplazar hacia la problemática de la razón, debido a la índole "lógica" de la tercera parte de la Trilogía. Pero como esta parte no solo finiquita toda la obra, sino también ofrece un acceso verdadero a ella, la cuestión de la racionalidad balthasariana pasa inadvertidamente al primer plano de la discusión, aunque se continúe preguntando por el amor, en lo que se refiere a su lógica en cuanto "lógica del amor" (6).

Pese a que Balthasar se opone decididamente a tal "lógica del amor" en un sentido hegeliano, hace suyo el problema de fondo, que emerge desde la permanente crítica abierta a Hegel y Kant (7). De ahí que el estudio de la relación razón y amor en la Teológica requiere una atención peculiar a las fuentes, ya que ellas echan luz sobre la densidad excepcional de la argumentación balthasariana, y también permiten apreciar mejor la originalidad del teólogo suizo (8), cuando pone de relieve una presencia viva del amor y su activa anticipación a la razón, precisamente en los ejes claves que articulan la racionalidad humana (9).

Articulación que se pretende verificar en la Teológica misma, allí donde la razón humana se encuentra con su propio dilema: o contentarse consigo o trascender a la infinitud que la anticipa, de tal modo, que emerja el "espacio intermedio", evocado por el autor con frecuencia. Tal estructura "triádica" de la racionalidad salta a la vista, no solo a través de los tres volúmenes de la obra, Verdad del mundo, Verdad de Dios y Espíritu de la verdad (10); también en la síntesis Sobre el conjunto de la obra, que Balthasar antepone a dichos volúmenes. Allí, el teólogo suizo insiste en la necesidad de reflexionar "sobre cómo la verdad infinita de Dios y de su Logos puede ser apta para expresarse en el estrecho recipiente de la lógica humana, no solo de modo vago y aproximativo, sino de forma adecuada" (11)

De ahí la cuestión decisiva que orienta el presente estudio: ¿Cuál es la función del amor en aquellos ejes cruciales de la argumentación balthasariana, que propone

(6) TROUPE E., La logique de l'amour. A propos de quelques volumes récemment traduits de H. U. von Balthasar, RTL 29 (1998) 202-228; O'DONNEL J., Truth as Love: the Understanding of Truth according to Hans Urs von Balthasar, Pacifica 1(1988) 189-211.

(7) Apokalypse der deutschen Seele. Studien zu einer Lehre von letzten Haltungen,I : Der deutsche Idealismus, 3. ed. Einsiedeln 1998, 562-619 y 91-135. Cf. SCHULZ M., Sein und Trinität, St. Ottilien 1997, 686-821; KLAGHOFER-TREITLER W., Karfreitag. Auseinandersetzung mit Hans Urs von Balthasars Theologik (Salzburger theologische Studien, 4) Innsbruck 1997, 196 pp.: los múltiples cuestionamientos que el autor propone a la Theologik, no siempre son logrados, pero invitan a seguir profundizando el pensamiento balthasariano.

(8) Cf. MEIS A., El Apriori filosófico en la Teológica de Hans Urs von Balthasar, VERITAS 11(2003), en prensa.

(9) Cf. PÉREZ HARO E., El misterio del Ser. Una Mediación entre Filosofía y Teología, en Hans Urs von Balthasar, Barcelona 1994, 451 pp., HENRICI P., Zur Philosophie Hans Urs von Balthasars, en LEHMANN K., KASPER W. (eds), Hans Urs von Balthasar. Gestalt und Werk, Köln 1989, 237-259.

(10) Theologik. I. Wahrheit der Welt, Einsiedeln 1985; II. Wahrheit Gottes, Einsiedeln 1985; III. Der Geist der Wahrheit, Einsiedeln 1987.-Por razones prácticas se cita la obra en su traducción española para facilitar la comprensión. Pero se agrega entre paréntesis las páginas correspondientes a la edición original alemana-. La corrección de estilo y estructura gramatical del presente estudio han sido revisadas por Dr.ph. Salvattori Coppola, Profesor de Filosofía del Lenguaje y de Redacción, escritor, actual Director Académico del Instituto Profesional de las Comunicaciones.

(11) TL 1, 23: La visión de conjunto que Balthasar ofrece en "Sobre el conjunto de la obra", TL I, 1123, es un valioso acceso tanto a la Trilogía como al pensamiento balthasariano, aunque es de menos envergadura que el Epílogo. 
traducir la lógica de Dios en la suya propia humana? ¿Cómo emerge el "entre”, que liga razón y amor? Se trata de dilucidar esta cuestión a la luz de la pregunta planteada respecto de la precomprensión en $T L 1$, su aparente contradicción en la $T L 2$ y su comprensión propiamente tal, mediante el don del Espíritu Santo, en TL 3. Se aplica un método de indagación basada en una lectura analítica coherente de la Teológica, y se pretende detectar el enganche preciso de la racionalidad con el amor a partir de una base estadística exhaustiva: las tantas veces en que el autor se refiere explícita e implícitamente a la ratio y su campo semántico (12).

\section{RATIO Y VERDAD DEL MUNDO}

Toda la argumentación del primer volumen de la Trilogía,Verdad del mundo, está dedicado a verificar la "precomprensión”, el Vor-verständnis de la cuestión, ¿en qué medida "la verdad infinita de Dios y de su Logos puede ser apta para expresarse en el estrecho recipiente de la lógica humana, no solo vaga y aproximativamente, sino de forma adecuada"? (13).

\section{a) La cuestión de la condición de posibilidad de la racionalidad}

El autor abre su argumentación en la Introducción con unas sugerentes preguntas:"... suponiendo, pues, que la razón cognoscente llegue a la convicción de que existe algo como verdad y que esta es propiedad del pensamiento y del ser y que regula su relación recíproca, ¿se dará entonces por satisfecha la razón? ¿No se percatará, más bien, de que solo entonces comienza la parte más fructífera de su trabajo, de que se le ha entregado un pasaporte que la autoriza a entrar en primer término al país del conocimiento, de que se revelaría más como insensatez que como razón en caso de satisfacerse con el primer éxito y suspender el examen recién iniciado?" (14). Estas preguntas, sin duda, articulan una primera intuición de la índole propia de la razón a partir de la convicción de que la verdad existe. Tal convicción abre el acceso al "conocimiento", que el autor designa "un país", es

(12) La estadística trasluce a la luz una frecuencia casi exclusiva de razón (Vernunft) y entendimiento (Verstand) en TL 1 (80), salvo algunas excepciones, en que el autor usa logos (5) y Logik (2); estos últimos dominan TL 2 (51), con menos referencias a la ratio y compuestos (27). TL 3 , por su parte, usa casi exclusivamente los vocablos entendimiento (Einsicht), comprensión (Verständnis), junto con conocimiento (Erkenntnis) (30 en total), fuera de logos, lógica (10) y razón (Vernunft), entendimiento (Verstand) (10). Estos datos arrojan a la luz un hecho muy iluminador para la comprensión del problema razón y amor, ya que el sufijo -nis designa el resultado del proceso de la actividad de la razón. Cf. DUDEN. 4: Grammatik der deutschen Gegenwartssprache, Mannheim, Zürich 1966, 380.

(13) TL 1, 23 (XXI): El problema emerge de la índole lógica a partir de su relación con la verdad, que cuenta con el Vor-verständnis, es decir, algo dado en cuanto resultado de la acción de comprender, pero anticipadamente. Esto demuestra que el autor integra un aspecto decisivo de la crítica de la razón.

(14) TL 1, 25 (11): La distinción entre Vernunft, que el autor califica de "erkennende" y el Verstand remontan en su etimología al siglo XVII, es decir, al uso que Kant hace de estos vocablos. Cf. DUDEN. 7: Herkunftswörterbuch. Etymologie, Mannheim, Zürich 1963, 739; 741. 
decir, una amplitud, dentro de la cual la razón humana podrá iniciar el descubrimiento de lo que es la verdad.

Avanza Balthasar hacia una mayor precisión de dicha relación entre existencia y esencia, al constatar: "Para saber si existe la verdad hay que contar previamente con una especie de preciencia de lo que ella es. Pero en tanto la razón se ocupa temáticamente de la cuestión de hecho, plantea solo de un modo indirecto la cuestión de la esencia, y solo con motivo de la cuestión de la existencia, sin ocuparse todavía, de un modo directo y con toda la pasión que el problema de la esencia exige, de la investigación de la verdad" (15). La razón se orienta, entonces, "primordialmente" por la existencia, que se supone conocida a la luz de una cierta "preciencia", una acentuación sobre la existencia, que el autor mantiene a lo largo de todo TL 1 y es fruto del permanente diálogo de Balthasar con Heidegger (16).

Resulta significativo que el teólogo suizo ejemplifica dicha "preciencia" mediante el punto de partida del amor. Esto le permite afirmar: el "primer acto de fe, de la confianza que se entrega, no es en absoluto irracional, es la sencilla condición previa para cerciorarse de la existencia de lo racional, en general" (17). El "acto de fe", es decir, de confianza constituye así una primera faceta de la condición de posibilidad de la "existencia de lo racional". Lo cual lleva al autor a desenmascarar el "racionalismo moderno, que pretendía reducir el campo de la verdad a algo puramente teórico y presuntamente aislable" (18), de tal modo,"que el ámbito de lo bueno y de lo bello cayera fuera de lo que el conocimiento puede comprobar y resultara abandonado a un arbitrio subjetivo siempre parecido, o bien al mundo privado de la fe y el gusto" (19). En efecto, los trascendentales se transforman en ideas vacías para Kant, y son "intrínsecamente contradictorios", según Nietzsche (20).

(15) TL 1, 25 (11): Dasein und Sosein son términos difíciles de traducir, por lo cual su distinción requiere finuras lingüísticas no siempre logradas en español, como se apreciará a lo largo del presente estudio: se trata del "ser y estar aquî" y "ser estar así".

(16) La influencia de Heidegger y referencias explícitas se encuentran en toda la obra de Balthasar, desde el Apokalypse der deutschen Seele. Studien zu einer Lehre von letzten Haltungen. III Die Vergöttlichung des Todes, Leipzig 1939,193-315, hasta Teológica 3. El Espíritu de la Verdad, Einsiedeln 1987 (Cf. TL 3, 3, 359), sobre todo, en TL 1, sin que Heidegger sea nombrado, en forma explícita. Tal vez se puede aventurar que el aporte de este filosofo es la relevancia de Gegebenheit, y toda la obra balthasariana es un esfuerzo por agregarle al Es el Er, pero más allá de Marion no solo la dimensión de gratuidad, sino de gratuidad trinitaria, personal. Cf. IMPERATORI M., Heidegger dans la "Dramatique divine" de Hans Urs von Balthasar, NRT 122 (2000) 191-210.

(17) TL 1, 27 (13): Como todo esfuerzo filosófico, se parte aquí de la certeza que, al ubicarla en el amor, no solo se opone a toda interpretación irracional; se acrecienta en la obra, en la medida en que el amor va emergiendo con mayor nitidez, sin que se defina dicho amor.

(18) TL 1, 31(19): El Sinn -sensus- enuncia en singular la justificación englobante, pero también apunta en plural a los sentidos: en este doble alcance resulta importante para la solución del problema razón y amor, en cuanto aproxima al enganche como el autor lo evoca en su constante atención a los aportes de la teología medieval.

(19) TL 1, 31 (19): La alusión a los trascendentales lo bueno y bello no solo significa una ayuda adecuada para la comprensión de la racionalidad, en relación a la verdad; tematizan además el núcleo central del pensamiento balthasariano, que enfatiza la centralidad del ser. Cf. MEIS A., Prodigalidad menesterosa: Significado teológico de los trascendentales en el método teológico de Hans Urs von Balthasar, Teología y Vida 32 (1991) 185-204.

(20) TL 1, 31 (18): Pese a que Balthasar explique la relevancia de los trascendentales para su pensamiento, cf. Epílogo y algunos estudios le prestan debida atención, hace falta un estudio detenido de la reinterpretación novedosa que Balthasar lleva a cabo en toda su obra y en su uso de los trascendentales. 
Allí donde comienza a tratar la Verdad como naturaleza, Balthasar sostiene que un tal racionalismo, del cual "la filosofía cristiana tendrá que cuidarse de favorecer" (21), solo puede superarse "simultáneamente con el irracionalismo a partir de una posición básica unitaria” (22). ¿En qué consiste esta posición unitaria? El autor lo explica a partir de una mayor precisión de cuanto entiende por racional y racionalidad. Argumenta en forma progresiva, partiendo de la interrelación del ser particular con el ser en su totalidad: "Comprensible y, en este sentido limitado, racional es la verdad, por el hecho de que el ser particular se da en su abertura realmente tal cual es y de que, por tanto, en ese lugar es aprehendida y penetrada una parte del mundo según su sentido y esencia" (23). La "posición unitaria", entonces, lejos de ser uniformidad o resumen se constituye a partir de una dualidad concreta, a modo de inclusión y ligado al "sentido", la dualidad de existencia y esencia.

Dicha dualidad del ser particular con el ser en su totalidad aporta una nueva precisión para la razón, que Balthasar enuncia de la siguiente manera: "Lo racional -en sentido estricto- del primer aspecto tiene su complemento inmediato en esta perspectiva ensanchante, dentro de lo cognoscible no conocido; más aún, es racional solo en la medida en que el conocimiento singular se destaca sobre este trasfondo de lo cognoscible en principio, aun cuando en ese momento no sea conocido. Estos dos momentos, pues, no se oponen uno al otro como lo racional y lo irracional; más bien constituyen en su unidad la estructura indivisible de la razón humana" (24). La razón humana tiene, por consiguiente, una estructura indivisible de dos componentes, que se compenetran de modo desproporcional.

Tal unidad desproporcional de momentos "conocidos" y "no-conocidos", es decir, de lo visible y lo oculto, conduce a una nueva distinción: la racionalidad, en el sentido estricto y en el sentido amplio. Pues constata Balthasar: "La racionalidad, en sentido estricto es un estado abierto de un ente singular conocido (tratándose en este caso de un estado de apertura que de algún modo pone término, remata), exige como condición de su posibilidad el estado de abierto del ser conocido en general (tratándose en este caso del estado de abertura que abre). Solo con el trasfondo de este ser conocido, pero no ya definible en su infinitud, se puede destacar el primer plano del ente singular en su condición de definible" (25). Aquí emerge la condición de posi-

(21) TL 1, 31(19). Cf. TL 3, 42: Balthasar manifiesta una reserva casi extrema frente a la crítica kantiana de la razón, sin desconocer su importancia. Probablemente el distanciamiento de Rahner, cuya destacada capacidad especulativa reconoce en la Teológica, tiene aquí su origen. Una valiosa comparación del pensamiento propio de ambos teólogos ofrece HOLZER V., Le Dieu Trinité dans l'histoire. Le differend théologique Balthasar-Rahner, Paris 1995, 195-430.

(22) TL 1, 31(20): El ritmo triádico que aquí se hace notar, es decir, racionalismo, irracionalismo, posición unitaria, es propio hasta en la estructuración gramatical del lenguaje balthasariano y se repite con frecuencia.

(23) TL 1, 41 (31): Para el significativo tema de lo particular/universal cabe remitir al clásico estudio de VIGNOLO R., Hans Urs von Balthasar: Estetica e Singolarità, Milano 1982, que todavía conserva su validez.

(24) TL 1, 42 (32): Lo que Kant divide en Vernunft y Verstand lo une Balthasar, sin desconocer lo que Kant pretende.

(25) TL 1, 42 (32): El estudio de DISSE J., Metaphysik der Singularität. Eine Hinführung am Leitfaden der Philosophie Hans Urs von Balthasars, Frankfurt 1996, tiene, sin duda, el mérito de haber profundizado esta faceta a partir de textos inéditos, que complementan los resultados de TL 1 , indudablemente, posterior al texto estudiado por Disse. 
bilidad de la racionalidad como "el estado de abierto del ser", no definible, pero sí interrelaciónado con el "ente singular" definible.

Agrega Balthasar: "Racionalidad en su sentido amplio significa por consiguiente ambas cosas a la vez: el saber acerca de la posesión real de una situación objetiva existente dentro de un todo del ser fundamentalmente abierto, es verdad, pero siempre desbordante en su concreción" (26). Resalta la opción básica de la racionalidad balthasariana, ligada a la concreción de la verdad siempre desbordante, dando al ser concreto aquella preferencia que enuncia la inversión del árbol de Porfirio, inversión que, indudablemente, constituye su propuesta de mayor relevancia (27).

La cuestión por la condición de posibilidad de la racionalidad humana, entonces, pone a descubierto una serie de distinciones sostenidas por una posición unitaria, que, a su vez, atestigua la índole dual constituyente de la realidad. Como tal, esta trasunta las funciones de la razón humana, apoyadas en un "punto medio".

\section{b) Las dos funciones de la razón y su punto medio}

Balthasar se adentra en la estructura interna de la misma racionalidad y su proceso cognoscitivo, al afirmar: "El conocimiento mundano es siempre ambas cosas: receptivo y espontáneo, medido y medidor. Ambos factores pueden estar acentuados y distribuidos en forma diferente... Pero, como quiera que estén distribuidos los acentos, el conocimiento es siempre dador de medida y receptor de medida y en esta duplicidad del medir y del ser medido, comienza y consiste la verdad. Es tanto producida (en cuanto intellectus agens) como comprobada (en cuanto intelectus passibilis) por el entendimiento cognoscente. En el fluctuante punto medio y en el equilibrio entre estas dos funciones de la razón (la recepción y la conformidad que se otorga, y el pronunciamiento de un juicio), se mueve la verdad" (28). Emerge aquí la dualidad al interior de la razón en calidad de ritmo propio, que el autor comprende como sus "dos funciones". Resalta también el "punto medio", en cuyo "equilibrio" acontece la verdad.

Cuando Balthasar trata El sujeto, constata dichas funciones de la razón, explicadas Balthasar en su interrelación con lo sensible: "también la sensibilidad, a la que se suele atribuir la función receptiva, es activa y espontánea a su modo, así

(26) TL 1, 42 (32): "Lo concreto", sin duda, constituye un concepto fundamental del pensamiento balthasariano, que se gesta transversalmente a lo largo de todo su obra en interrelación con la captación de la Gestalt, que el joven Balthasar describe magistralmente en Goethe. Cf. Apokalypse der deutschen Seele I: Der deutsche Idealismus, 3. ed., Einsiedeln 1998, 407-514, sobre todo, 445ss. Para una breve visión de conjunto de la proyección cristológica cf. FABER E. M., Universale Concretum bei Hans Urs von Balthasar, Communio. Internationale katholische Zeitschrift 29(2000) 258-273.

(27) En este punto, Balthasar no solo es innovador para el actual desarrollo de la filosofía (Cf. DISSE J., Metaphysik, 61-64), sino supera también sus propias fuentes, como permite concluir un estudio comparativo entre Dionisio y Gregorio de Nisa. Cf. MEIS A., Die Verborgenheit Gottes in den Kommentaren zum Hohenlied in Gregor von Nyssa und Dionysius Areopagita, ETL 77 (2001) 73-107. Sin embargo, haría falta un estudio más detenido de este aporte balthasariano.

(28) TL 1, 44 (34): El autor conjuga Verstand y Vernunft. El Verstand lo comprende fundamentalmente como participación en el "göttlichen Verstand": TL 1, 43(35) y la Vernunft como abertura trascendental. 
como, a la inversa, la razón, a la que se asigna el papel espontáneo, es a su modo receptiva en cuanto razón percipiente (intellectus passibilis). La espontaneidad de la sensibilidad es inclusive mayor, a primera vista, que la de la razón, pues es la productora de la energía sensible específica, descompone y distribuye el objeto simple en la riqueza de su quíntuple espectro, mientras que la espontaneidad espiritual parece limitarse a reproducir el objeto tal cual es en sí" (29). Con esto se ponen de relieve dos componentes básicos de la racionalidad, que también son propios de la "realidad del amor", como Balthasar demuestra (30), insistiendo en la índole objetiva de tal dualidad: "En tanto la espontaneidad del conocimiento está totalmente al servicio de la receptividad (intellectus agens como instrumento del intellectus passibilis), de la razón que recibe los datos, el conocimiento de la verdad y la verdad del conocimiento equivalen a la más estricta objetividad" (31).

Sucede lo contrario afirma Balthasar al describir la Libertad del objeto, cuando "se separa definitivamente lo que en Tomás de Aquino era una unidad indisoluble: el pensamiento que juzga (intellectus agens, dividens et componens) y el pensamiento receptivo (intellectus passibilis). Se quita así al pensamiento "racional" su carácter de misterio y al pensamiento intuitivo, comprensivo, la posibilidad de ser probado y la estructura lógica, y se le condena a la soledad y a la irracionalidad. Pero estos dos aspectos del pensamiento humano, ciertamente distinguibles y cada vez más claramente destacables, solo juntos constituyen la verdadera fuerza y plenitud de aquel. Un único conocimiento, tanto lógico y judicativo como intuitivo, está frente a un único objeto, tanto aprehensible racionalmente como íntimo y peculiar" (32). De ahí que el teólogo suizo concluya: "No ver ninguna contradicción, ni siquiera una oposición, en estas dos partes del ser fue siempre un rasgo característico de la sana filosofía" (33); es decir, aquella filosofía atenta a la "índole de misterio" de la razón, basado en el misterio del ser mismo (34).

(29) TL 1, 48-49 (40): Balthasar inicia aquí sus referencias a Tomás de Aquino, que se repiten hasta el final de la Trilogía, lo cual pone en cuestión la frecuente afirmación respecto a la ausencia del Aquinate en Balthasar, afirmación que requería una revisión más intensa, pese a que los estudios al respecto se incrementan notoriamente. Cf. LAFONTAINE R., Quand K. Barth et H. Urs von Balthasar relisent le de Trinitate de Thomas d'Aquin, NRT 124(2002) 529-548.

(30) TL 1, 49 (40): El autor no define el amor, pero señala tantas facetas válidas de este fenómeno antropológico teológico, que, no cabe duda, el amor es lo más central de su pensamiento, y está lejos de ser una mera sensación. Afirma: solo los que aman saben quién es Dios y por eso los teólogos los deben escuchar. Cf. supra, nota 1.

(31) TL 1,74 (73).

(32) TL $1,85 \mathrm{~s}(84)$.

(33) TL 1, 85s (84): Aquí cabe recordar todo el esfuerzo de G. Siewerth y de F. Ulrich de reinterpretar a Tomás de Aquino, reinterpretación que actualmente recibe una atención renovada, sobre todo, por estudiosos talentosos jóvenes. Cf. TOUPRE E., "Actualité" et "potentialité" de Gustav Siewerth, en REIFENBERG P., VAN HOOFF A., (eds) Gott für die Welt. Henri de Lubac, Gustav Siewerth und Hans Urs Urs von Balthasar in ihren Grundanliegen, FS W. Seidel, Mainz 2001, 146-155; Cf. ídem, Siewerth "après" Siewerth. Le lien idéal de l'amour dans le thomisme spéculatif de Gustav Siewerth et la visée d'un réalisme transcendantal (BPL, 49) Louvain-Paris 1998.

(34) Cf. Gloria 5, 563-75. Es clave la comprensión del actus essendi de Tomás de parte de G. Siewerth en cuanto consta que el ser no es Dios sino su imagen por excelencia. Cf. SCHULZ M., Sein, Welt und Mensch als Gleichnisse des dreieinigen Gottes.Trinitätsontologische und offenbarungstheorethische Überlegenungen im Anschluss an Gustav Siewerth, en REIFENBERG P., VAN HOOFF A., (eds), o.c., 246-266. 
Cabe atenerse a tal índole, insiste Balthasar: "Solo un espíritu impermeable a lo noble y a su necesidad de defensa deplorará este ocultamiento de todo lo mejor. Quizá lo tomará por falta de racionalidad, hablará de la irracionalidad de todos aquellos objetos que no son accesibles al conocimiento anónimo, común a todos. Pero un castillo real no es invisible solo porque sean pocos quienes pueden visitarlo. Toda verdad es racional, pero no todo entendimiento está capacitado para conocer toda verdad" (35). La índole mistérica de la racionalidad no carece, entonces, de objetividad, pero sí desafía la capacidad de la razón. ¿En qué consiste tal capacidad? ¿Es óntica o volitiva?

De hecho, prioriza el aspecto volitivo, pero deja entrever de inmediato la implicación óntica, cuando analiza la Libertad del sujeto: “...en este modo de ver no hay un irracionalismo que considere el campo del pensamiento como finito y condicionado, y el campo de la voluntad como infinito y condicionante. El hecho voluntario del abrirse, en cuanto tal, no es irracional, es más bien el sentido supremo y definitivo de toda ratio; la justificación última de todo ser en su esencia y en su existencia, la presuposición a la cual toda posición puede al fin reducirse, y sin la cual todo ser y acaecer permanece incomprensibles y carentes de sentido" (36). La razón posee, entonces, la capacidad de "abrirse" voluntariamente, lo cual, en cuanto "sentido supremo y definitivo" y "justificación última de todo ser", se transformará en base certera de la relación razón y amor, de tal modo que ya se vislumbra una posible solución balthasariana del problema planteado.

Advierte el teólogo suizo: "El concepto de amor pertenece al concepto pleno de verdad, así como el de voluntad, al concepto pleno de conocimiento. Desde luego, es posible que alguien que no ame conozca también datos exactos. Pero su entendimiento se asemeja a la mirada del miope: aguda, más aún, agudísima para sectores parciales, es incapaz de abarcar amplias perspectivas de la verdad" (37). Se postula aquí una inteligibilidad del ser mismo en su esencia y en su existencia, opuesta a lo que pretende "el camino del racionalismo y del idealismo místico"; vale decir: "echar la llave a las puertas de los sentidos, para escuchar en nuestro interior la voz de la razón, ver la luz del espíritu, único modo de liberarnos del engaño y abrir el reino de la verdad" (38).

No solo rechaza tajantemente tal pretensión en su análisis del Mundo de las imágenes, ni se cansa en su esfuerzo por rescatar la apertura de la razón al ser en interrelación con el amor, sino avanza un paso más, cuando afirma: el "logos del ser... se abre ahora a un logos intersubjetivo que, fluctuante entre la unidad de la esencia y la pluralidad de las personas, recrea la unidad de la palabra en forma de discurso y respuesta. Este logos tiene una forma indecisa en lo más íntimo, una forma inestable: a fin de ser una real conversación se apoya en los firmes pilares del sujeto individual" (39). El autor, más allá del uso de logos en lugar de "razón", uso que se hará exclusivo en $T L 2$, aquí encamina su argumentación hacia la intersubje-

(35) TL 1, 102 (107).

(36) TL 1, 112 (117).

(37) TL 1, 112 (117).

(38) TL 1, 138 (149).

(39) TL 1, 170 (192). 
tividad, evidencia decisiva para las dos funciones de la razón en su interrelación con el amor.

Concluye Balthasar: "el sentido total de la verdad se muestra como amor. Pues tan pronto como la dirección del develamiento del ser excede al yo para realizarse en el tú, tan pronto como el logos del ser se transforma en diálogos, en el sentido de una ininterrumpida comunicación, aparece también el amor como definitiva interpretación de todo el movimiento" (40), orientado por la trascendencia a partir de un eterno prius, que engloba a la razón permanentemente en su necesidad intrínseca de trascender.

\section{c) La trascendencia de la razón finita por la infinitud como su eterno prius}

En su interpretación de la Verdad como situación, al rechazar la preocupación por un personalismo excesivo de la verdad en desmedro de su carácter racional (41), Balthasar avanza hacia otra dualidad de la racionalidad: lo individual y universal. Insiste: "En la medida en que este lado natural de la existencia encierra ante todo, en estructura y ley, lo común a la esencia de una especie o género, la abstracción de lo individual es legítima y, sin dañar a la verdad (abstractio non mentitur) puede prescindir del caso particular (y también del eventual sujeto de conocimiento). La racionalidad del conocimiento tiene aquí la propiedad de una universalidad suprapersonal" (42). El autor justifica la "universalidad suprapersonal", pero rescata la racionalidad de lo individual por medio de aquel giro llamativo que antepone lo individual a lo universal y que como tal caracteriza todo el pensamiento balthasariano.

De ahí que reitera: “...en modo alguno decimos que en esta situación la verdad sea menos "racional", menos cognoscible que en su forma natural y abstracta. Las palabras individium ineffabile significan solo que lo individual jamás puede traducirse, sin dejar restos en lo universal, pero en modo alguno significa que por eso no sea también cognoscible a su modo" (43). Además, "Si del lado de lo universal y abstracto bastara una actitud cognoscitiva impersonal, puramente objetiva, entonces la ratio, que debe adecuarse a la recepción de lo personal y único, tendría que satisfacer hasta a las suposiciones y condiciones previas de lo personal. Pero el hecho de que un objeto postule ciertas condiciones previas para ser conocido, y que por eso solo sea accesible a quien acate esas condiciones, no significa evidentemente que él en sí mismo sea menos cognoscible, menos racional que cualquier otro. Su racionalidad tiene igualmente valor universal; solo el conocimiento de tal valor está atado a ciertas condiciones, que cualquiera no está en situación de cumplir" (44).

Balthasar se adentra todavía más en este problema, diciendo allí donde trata $L a$ Verdad como Misterio "que es continuo el tránsito de las estructuras universales al ser individual... Ambos aspectos del plan de sentido de un ser se compenetran íntimamen-

(40) TL 1, 172. (193)

(41) TL 1, 177. (201)

(42) TL 1, 178 (203).

(43) TL 1, 178 (203): Está en cuestión el complejo concepto balthasariano de persona, que no se identifica con individuo, sino es concebido como singular concreto. Cf. MEIS A., La persona, en cuanto singularidad concreta, según Hans Urs von Balthasar, Teología y Vida 42 (2001) 1-28.

(44) TL 1, 179 (204). 
te, constituyen juntos su contenido de verdad y de razón. De ahí que el conocimiento de esta idea tendrá que ser tanto definitivo y normativo como histórico y consecutivo" (45). Tal dualidad "transitoria" atestigua, sin duda, que el misterio del ser "no es un caos irracional, sino tanta luz, tanto orden, tanta verdad, que el necio espíritu humano jamás dominará esta riqueza. La existencia es un don y solo puede recibirse con agradecimiento y el eterno más, que excede a todo lo captado y que se muestra en la hondura del ser y de la verdad, exige, según ya se dijo, la fe como propiedad inmanente a todo saber" (46), una "intelección" más allá de la mera visión exterior de los sentidos como "un leer al ser por dentro (intus legere)" (47). Resalta la relevancia del exceso, en cuanto positividad de una racionalidad auténtica dual e interna.

Por eso mismo, advierte dentro de su análisis de la Finitud e Infinitud: “...el hecho de que el entendimiento (Verstand) finito, al abrírsele el ser total en su carencia de límites, se vea obligado a afirmar la existencia del ser absoluto y de la verdad absoluta; y de que, por la fuerza de esta afirmación trascendente que rebasa infinitamente a la imagen singular y al concepto finito, prueba que la razón finita misma solo puede realizar su obra porque en él la alienta una orientación hacia la infinitud. En camino hacia esta eterna verdad y desde siempre a través de la señal de todos los objetos finitos, la razón se sabe oscuramente contemplada y llamada por ella. Así, pues, la razón humana no está encerrada en la finitud; inclusive en cuanto razón puede realizar su obra finita de conocimiento de las cosas finitas solo por tener ya desde siempre contacto con lo infinito" (48). Es decisiva, entonces, la apertura de la razón a la infinitud, comprendida, como connatural a la razón, anticipada por la infinitud.

Según el teólogo suizo, "El hombre tiene por eso un derecho, y hasta un deber, de no contentarse con la forma limitada y concluyente de la ratio. Pero, además, debe saber, no solo que la ratio en modo alguno es simplemente esa limitada y limitativa función, como a veces se la caracteriza, sino también que la inteligencia creadora lleva en sí una expresión y como un sello de la inifinita verdad divina. Esto es lo que se ha de oponer al irracionalismo de la "filosofía de la vida", que solo representa una reacción al racionalismo estrecho. No es propio de la "vida" conocer la verdad por contraposición a la "razón", sino de la razón, que siempre se trasciende a sí misma, el rebasar una y otra vez sus conquistas siempre finitas" (49). Resalta aquí el continuo trascenderse la razón a sí misma como su ritmo constitutivo, en cuanto marcado por la infinita verdad divina.

Por eso, Balthasar, entrando en la Ocultación, concluye: no "se puede decir que la racionalidad del conocimiento finito pudiera ser puesta en duda, porque este conocimiento esté obligado a reconocer el conocimiento divino superior a él, y no idéntico a él. Lo único cierto es que el sujeto mundano en su autocaptura se comprende como un sujeto ya aprendido y englobado, que su conocer tiene en su forma interior el eterno prius del ser conocido" (50). Lejos de contradecir este prius, la autonomía de la razón humana queda reforzada por medio de su índole creatural.

(45) TL 1, 180 (204).

(46) TL 1, 187 (214).

(47) TL 1, 203 (236).

(48) TL 1, 246 (287).

(49) TL 1, 246- 247 (288. 289). 


\section{d) La razón creatural}

Balthasar confirma lo expuesto, rechazando: "El acto de fe tendría, pues, por así decirlo, dos tiempos: el primero, dentro de la razón natural autónoma, que, sobre la base de su evidencia es conforme a los fundamentos de la razón, presta la obediencia de la fe. El segundo tiempo este acto mismo del sometimiento, en el cual la razón, apoyada en su propia intelección, rebasándose a sí misma, se arrojaría en el abismo de la verdad trascendente de Dios. Pero en tal justificación racional del acto de fe, el primer paso aparece como racionalista, y por ello, como irracional" (51). Sin duda, el ser anticipado por la verdad infinita y la apertura congénita a tal anticipación, capacita a la razón para su realización congénita creatural.

En efecto, "Es propio de la disposición originaria de la ratio creatural, que ella conozca implícitamente su carácter creado, de manera que puede extraer explícitamente la conclusión acerca de la existencia de su Creador. En la condición, que tiene todo comprender, de estar siempre ya comprendido por el comprender de Dios, se encuentra prefigurada dentro de la razón natural la forma de la fe. Y cuando el hombre se decide libremente a realizar este acto de sometimiento de fe al englobante saber de su Señor y Creador, obedece simultáneamente a su naturaleza, o mejor dicho, al mandato del Creador impreso en su naturaleza misma. Entonces, aquel segundo paso del acto de fe no tiene ya el carácter irracional que le es anexo cuando se busca la racionalidad en una autonomía, semejante a la divina, de la evidencia interna. No es que la razón se procure primero una especie de visión general acerca de Dios, su existencia y su esencia, para solo entonces doblegarse a la visión de Dios" (52). No hay, entonces, sucesión de razón y fe, sino simultaneidad, es decir, compenetración mutua entre criatura y Creador.

Tal compenetración es de índole desproporcional, ya que "La verdad es siempre más grande que lo que un entendimiento finito capta de ella, y en la conciencia de ese su ser mayor es donde dicho entendimiento la capta... Pero, no bien se advierte que la primera evidencia tiene el carácter de estar englobada por la verdad cada vez mayor de Dios, estas aspiraciones de la razón finita desaparecen para hacer lugar a una actitud que espera de Dios la medida de la verdad por conocer" (53). Sin duda, la argumentación balthasariana alcanza aquí su punto culminante a través de aquella dinámica "siempre más", que asemeja la racionalidad al amor en cuanto este conlleva un reconocimiento amoroso, la "obediencia del entendimiento", naturalmente incluida en la autoconciencia de un espíritu creado.

El autor afina su argumentación en la parte de la Confesión, insistiendo: "No es verdad que el impulso natural del entendimiento esté encaminado a querer saberlo todo. Prescindiendo de que hay innumerables cosas que no interesan al entendimiento, este, en su calidad de entendimiento de un ser que ama, querrá saber del amado

(50) TL 1, 253 (295): La traducción “ocultación” no resulta muy feliz para traducir el término original: Geborgenheit, que tiene que ver con cobijo.

(51) TL 1253 (296).

(52) TL 1, 254 (297).

(53) TL 1, 255 (298). 
solo lo que este quiera comunicarle. Juzgará desamoroso e indigno querer investigar los secretos que el amado le silencia con buenos motivos, motivos siempre del amor" (54). De tal modo, “...pertenece a la esencia del entendimiento humano pronunciar un juicio acerca de la verdad de las cosas (como intellectus dividens et componens)" (55). Resalta la relevancia decisiva del amor en el auténtico funcionamiento de la razón, en cuanto "entendimiento", Verstand, que se abre a una certeza definitiva dentro de un nítido acontecer comunicacional, personal, creatural.

En síntesis, la ratio encuentra su condición de posibilidad connatural en el ejercicio dual dentro del ámbito finito a partir de la anticipación por la infinitud, sostenida por el prius eterno del Creador con una apertura congénita al Logos de Dios. Con esto Balthasar no solo logra esbozar, de modo acertado, la "precomprensión" de una Teo-lógica, verifica, además, el amor como única certeza confiable de la razón subistente.

\section{LA RAZÓN- LOGOS Y SU CONTRADICCIÓN EN LA VERDAD DE DIOS}

Pese a que la verdad de Dios irrumpe de modo abrupto, al iniciarse la argumentación de la segunda parte de la Trilogía, Verdad de Dios, Balthasar advierte: "La pregunta fundamental que ahora se ha de plantear es: ¿Puede la lógica humana proporcionar una base humana sólida para la representación auténtica de la lógica divina? (56). Esta pregunta, lo mismo que en el volumen anterior, orienta todo el desarrollo de la segunda parte de la Trilogía.

\section{a) En busca de una "lógica del amor"}

La verdad de Dios se presenta en forma abrupta, en cuanto Logos encarnado (Jn 14, 6), pero también el concepto de la razón humana sufre amplicaciones y alteraciones significativas, desde el paso de la ratio latina al logos griego. De hecho, el autor recuerda" En Marcos, Cristo, interrogado acerca del mandamiento principal, añade la "mente" (dianoia), y el escriba confirma su palabra con las tres expresiones "corazón", "inteligencia" (synesis) y "fuerzas" (Mc 12, 29-33). Lucas inserta igualmente en el mismo pasaje las cuatro palabras "corazón, alma, mente (dianoia) y "fuerzas" (Lc 10,27). Mateo, los tres elementos: "corazón”, “alma”, "mente” (Mt 22, 37): evidentemente, la "dianoia" contaba ya con una sólida base en la tradición, tal y como esta se remonta a Jesús" (57).

Una vez rescatado los componentes bíblicos de la ratio, en cuanto logos, en el apartado Lógica y Amor, el autor entra de lleno a la problemática "lógica del amor", iniciando una extensa justificación del Blondel (58): “Aquí se plantea la pregunta,

(54) TL 1, 257 (301).

(55) TL 1, 264 (310).

(56) TL 2, 67 (61).

(57) TL 2, 31 (27).

(58) La influencia de Blondel sobre el pensamiento de Balthasar no se ha estudiado con debida atención, pese a que estudios recientes insisten en ella. Cf. TROUPE, La logique de 1'amour, $205 \mathrm{ss}$. De todos modos, parece sugerente la observación de PLAGA U., o.c., 5: toda la obra 
¿sigue existiendo después de todo una lógica para un conocimiento tal, que se "elimina" en el amor? Un acercamiento a una respuesta afirmativa lo ofrece Maurice Blondel con su postulado "debe existir una lógica para la vida moral... ¿Cómo puede haberla, si en la lógica domina el principio de no contradicción, en cambio en la vida el bien y el mal se contradicen mutuamente de forma real y, por tanto, eliminan el principio de no contradicción...? Resulta posible, si nos diéramos cuenta de dónde reside el verdadero origen de los principios lógicos: en su separación respecto a nuestra vida viva, que se debe decidir libremente. Pues en los hechos mismos no hay nunca contradicción ni tampoco identidad (son solo semejantes entre sí)" (59). Balthasar hace suyo el postulado de la lógica de la vidablondeleana, que se sitúa "entre" extremos excluyentes.

Balthasar continúa: "en nuestra acción cambiante contraponemos las cosas, según se inserten o no en nuestro destino: se contradicen mutuamente en relación con nuestra tendencia, respecto a la decisión relativa a nuestra orientación global. Lo debido, pero perdido, es una privación (steresis) ya no eliminable, que, solo considerada desde fuera, aparece como una pura negación (apophasis). En tal considerando, la "razón especulativa" vinculada solidariamente con el uso real y actual de la razón práctica", queda artificicialmente separada de esta, con lo cual se originan "palabras" y "conceptos exangües" que después, en una inclusión y exclusión puramente abstracta, producen una simple logología (logica escolástica) al margen del ser real" (60). De tal modo, Balthasar verifica el aporte de Blondel invocando el ser real, desechado por la lógica abstracta (61).

El teólogo suizo admite, “... esta lógica abstracta no carece de utilidad: sus determinaciones de identidad sirven ante la decisión como advertencia y prueba de la conciencia moral frente a los dogmatismos de los simples impulsos y de la razón abstracta, y, además, el carácter acósmico del principio de no contradicción remite esta conciencia moral más allá de cualquier instalación en un pensar y actuar intramundanos: la elección pura significa siempre el todo: ser o no ser. En este sentido, "la negación (recibe) una justificación subordinada", pero nada más: No existe una lógica puramente formal, cada pensamiento es acto, y cada acto es iniciativa y síntesis", por lo cual "la lógica ideológica (es) solo una expresión parcial de la dialéctica de la acción". Sin embargo, ¿adónde va a parar la lógica de esta? Allí, donde cualquier decisión concreta sobre miles de posibilidades contiene en sí una reflexión en favor de una realidad, que se ha de disponer" (62).

Debido a ello, Balthasar consolida su comentario: "El acto es al mismo tiempo toma de posesión (ganancia) y renuncia: ambas, con vista al sentido global (logos real) de nuestra existencia. Esta lógica real, o de la vida, puede quedar expresada

balthasariana parece ser una concreción de la famosa frase de Blondel, “...para encontrar a Dios, no debemos rompernos la cabeza, sino el corazón”: BLONDEL M., L'Action (1893). Essai d'une critique de la vie et d'une science de la practique, Paris 1950, 374-375.

(59) TL 2, 33 (29)

(60) TL 2, 33 (29)

(61) Cf. el estudio sugerente de SERVAIS J., De la logique formelle à la logique morale selon, M. Blondel, Gr 82 (2001) 761-785.

(62) TL 2, 34-35 (29). 
completamente en formas científicas..." (63). Pero "este trabajo de conseguir la autoposesión tiene en perspectiva la lógica integral... las cosas solo exigen sacrificios relativos, pero la visión espiritual del principio de contradicción introduce en una vida hiperracional. La lógica racional solo puede estar viva dentro de la decisión moral, pero la moralidad solo puede existir gracias al principio de contradicción de la lógica formal: como realización de la libertad mediante la "mortificación", o como su pérdida" (64). Emerge asi la posibilidad de integrar la contradicción en la lógica, gracias a la atención que presta Blondel a la vida real en su decisión libre.

Balthasar concluye: "Hasta aquí la justificación de Blondel de una lógica vital que sobrepasa la lógica abstracta del conocimiento, y que para él solo tiene sentido con relación al Logos absoluto, divino y en última instancia divino-humano, como respuesta a él. Pues a la postre, no se trata del valor de la autorrealización, sino de la norma del amor a la totalidad de la verdad" (65). La lógica vital, entonces, remite al amor de la totalidad de la verdad y como tal al Logos absoluto, quien le da sentido, a modo como a la razón creatural le viene el sentido último del ser, brindado por el Creador. Sin embargo, el Logos absoluto, en su instancia divina-humana, plantea más allá de la esfera creatural una exigencia trinitaria.

\section{b) La exigencia de una lógica trinitaria}

En efecto, cuando Balthasar se refiere al "Logos total, con respecto al cual el creyente toma su decisión..." (66), advierte: "es una vasta esfera de lógica trinitaria que de algún modo debe ser experimentada para conocer la verdad..." (67), aunque debe admitirse también la existencia de la "estructura triádica de la lógica mundana" (68). Emerge así, con mayor claridad, la relación desproporcional entre la lógica trinitaria de Dios y la lógica mundana del hombre, semejante a la de la razón finita con la infinitud, pero interrelacionado con el aspecto práctico, la decisión.

El teólogo suizo establece el nexo indispensable, cuando afirma en la Lógica ana-lógica en el ámbito del mundo: "Una teológica, en la que la Lógica de Dios adopte la forma concreta de una lógica creada, no puede ser sino trinitaria. Pero, dado que, como se ha señalado, la verdad es el Logos hecho hombre, no se puede hablar de una "cristología descendente" ni de una "cristología ascendente"... debe existir en el ámbito del mundo una representabilidad de lo trinitario, con la que el Logos puede y debe conectarse en su autoexpresión, que se explica. Pero antes de que esta autoexplicación se haga temática, hay que abordar los intentos del pensamiento humano por descubrir desde sí mismo algo de lo trinitario en el ser del mundo" (69).

Balthasar se detiene en el análisis de la "estructura triádica de la lógica mundana", constatando: "ni una "identidad" ni una simple "diferencia"... pueden expresar la estruc-

\footnotetext{
(63) TL 2, 34 (30).

(64) TL 2, 35 (31).

(65) TL 2, 35 (31).

(66) TL 2, 36 (31).

(67) TL 2, $36(31) ; 39$ (33).

(68) TL 2, 39 (33).

(69) TL 2, 39 (33).
} 
tura del ser real del mundo. Una lógica construida sobre estos principios $(A=A ; A / B)$ es un abstracto producto residual de su verdadera constitución y, por ello, como máximo, un medio auxiliar secundario, con cierto poder de convicción, para no perder dentro de lo relativo la incondicionada exigencia de decisión". En lo real, la diferencia, lo "otro que yo mismo", se ve desde siempre superada por un tercero, en cuyo interior puedo ante todo constatar esta alteridad. Los opuestos no son indiferentes, sino siempre diversos el uno para con el otro" (70). Los conceptos "diferencia", "otro", "tercero" y "oposición" atestiguan, sin duda, que la argumentación balthasariana está avanzando hacia el meollo de la racionalidad que propone la Teo-lógica (71).

En efecto, el teólogo suizo afina su comprensión trinitaria en contraposición al pensamiento de Agustín y luego de Hegel, pensadores quienes "han intentado iluminar radicalmente el misterio trinitario del ser" (72). Constata Balthasar, cómo el obispo de Hipona no se atreve partir del amor intrahumano, busca la imagen de la Trinidad dentro de la persona espiritual individual, es decir, en el ser del espíritu como mens, notitia, amor y acota: "Notitia, sin embargo, es algo más que una simple autoconciencia, es un conocerse actual, en el cual esto mismo -en constraste con otro que sea cognoscible - se contrapone reflejando (con un verbum cómo proles) a su espíritu autocognoscente (que se ha conocido y amado ya desde siempre)" (73). Por eso, el teólogo suizo concluye: "la lógica triádica de Agustín reclama una imagen contrapuesta y complementaria, que haga saltar la estrechez del sujeto encerrado en sí mismo" (74). Refiriéndose a Hegel, Balthasar aprecia la imposibilidad de "que entremos aquí en la inmensa obra de la lógica hegeliana, pero tampoco queremos cometer la necedad de juzgarla desde fuera" (75). Por eso, el autor analiza en un pasaje de la Filosofía del Derecho, el movimiento dialéctico, que en el plano descrito es el del amor personal y es descrito como "la conciencia de mi unidad con otro" de modo "que solo alcanzo mi autoconciencia como supresión de mi ser para mí". Por primera vez se habla aquí del "otro", en masculino, mientras que, en todas las operaciones dialécticas precedentes, para ganarse a sí mismo el uno se convertía cada vez en un "otro" caracterizado como un objeto". La segunda cuestión sorprende en el movimiento dialéctico, es que siempre va del uno (que experimenta su finitud) hacia el otro, por tanto discurre "intencionalmente"; es decir, nunca parte de uno dado con anterioridad al uno o al otro" (76).

(70) TL 2, 40 (34): Los opuestos evocan, sin duda, la relatio oppositio, clave desde el aporte del magisterio, basado en Tomás de Aquino, DH 1330

(71) LUCIANI RIVERO R. F., El Misterio de la diferencia. Un estudio tipológico de la analogía como estructura originaria de la realidad en Tomás de Aquino, Erich Przywara y Hans Urs von Balthasar, y su uso en teología trinitaria (Analecta Gregoriana 285 B,101), Roma 2002, 628s. El autor aborda el problema de la diferencia con profundidad, pero queda la duda que despierta la ausencia de Hegel en esta investigación y, por lo mismo, de otros "adversarios", con quienes los tres teólogos estudiados discuten explícita o implícitamente el pensamiento de Balthasar. Una atención nítida a tales opositores, sin duda, hubiese permitido apreciar mejor la originalidad del estudio, pues la bella visión de conjunto, hilada tan finamente, hubiese recibido aquellos contornos que develarían mayores profundidades del misterio del "otro".

(72) TL 2, $41(35)$

(73) TL 2, 42 (36).

(74) TL 2, 44 (37): Pues con el amor interpersonal peligra la unidad de sustancia que se ha de mantener.

(75) TL 2, 49 (42).

(76) TL 2, 49 (49). 
Aprecia Balthasar: "Estos dos aspectos hacen aparecer siempre lo "otro" como un elemento negativo a través de cuya "mediación" lo uno (con la negación de la negación) alcanza su verdadera positividad. Lo otro es siempre "mi otro". En ese sentido resulta lógico señalar la eliminación de las limitaciones de lo uno (que es una contradicción en sí mismo) como su muerte. Pero si esta muerte del individuo viviente se describe como la forma de su "eliminación", que, a su vez, queda determinada por Hegel en su sentido preciso de forma triple ("poner fin", "conservar", "ser absorbido" como un "momento" por un todo superior), entonces esta determinación vale en la teológica de Hegel persistentemente, ya que también la muerte del individuo personal (sin su resurrección personal) queda sometida a ella..." (77).

El teólogo suizo evalúa críticamente lo expuesto y afirma: "Tras esta perspectiva se entiende que "lo positivo" para Hegel no tiene "ningún sentido de por sí"; al contrario, está en sí mismo absolutamente referido a lo negativo", y viceversa; ello, solo porque el tránsito a lo otro siempre se entiende como distanciamiento y no como amor (o desposeimiento amoroso); porque, por tanto, el amor como tal se hace lógico y en última instancia desaparece completamente en el saber absoluto, dado que la mayoría de las veces es descrito por Hegel solo como "sensación" (78). Este enjuiciamiento de Balthasar, respecto de Hegel, resulta decisivo para la comprensión de la relación razón y amor, en cuanto identificación de ambos, que el teólogo suizo rechaza decididamente, apoyándose en Tomás, interpretado por Siewerth, pero retomando lo argumentado en Blondel.

En síntesis, Balthasar reafirma: "Con respecto a esto, deberíamos remitirnos a la afirmación de Blondel, la "contradicción (antiphasis) en cuanto lógica solo posee una "legitimidad subalterna" para la dialéctica de la vida, y solo surge como contradicción real en la oposición del mal contra el bien. También habría que remitirse a la vibration originaria de Claudel, es decir, a la relación subsistente entre los seres (y eso no solo entre el uno y el otro, sino entre el uno y el todo), que después adopta una forma más concreta en la intersubjetividad de los dialógicos" (79). Está en juego, entonces, una demostración más que "racional" (80).

\section{c) ¿La acogida del Logos divino por el logos humano es posible?}

Una vez precisado su enjuiciamiento de Blondel y Hegel, Balthasar aborda la pregunta fundamental: ¿Puede la lógica humana proporcionar una base humana sólida para la representación auténtica de la lógica divina? (81). De este modo, retoma el planteamiento: el hombre natural sabe lo que es la Ética y la razón práctica (Vernunft) (82), e interrelaciona este dato con la Lógica Bíblica, afirmando: "Quizás

(77) TL 2, 51 (43)

(78) TL 2, 51 (44): Muestra W. KERN, Das Verhältinis von Erkenntnis und Liebe als philosophisches Grundproblem bei Hegel und Thomas von Aquin, Scholastik 34 (1959) 394-427, que el joven Hegel conoce la significativa interrelación entre razón y amor, que se pierde bajo el peso de la creciente racionalización, a que Hegel somete su pensamiento.

(79) TL 2, $51(44-45)$.

(80) TL 2, 59 (52).

(81) TL 2, 67 (61).

(82) TL 2, $80(75)$. 
en ningún otro ejemplo como en las parábolas de Jesús, orientadas a la praxis (o sus exigencias y consecuencias), resulta tan claro que la lógica divina se puede y se quiere expresar en lógica humana, sobre la base de una analogia linguae, y en última instancia -pese a todos los reparos- también entis, que se consuma en Cristo, Dios y hombre en una sola persona" (83).

Subrayada así la no-conceptualización de Dios, pues “¡Dónde queda aquí, ante todos los racionalismo filosóficos y teológicos, desde Eunomio hasta Hegel, la advertencia repetida constantemente por los grandes teólogos, de que ninguno de nuestros conceptos alcanza a Dios..." (84); y subrayada como debida respuesta a los racionalismos de los gnósticos (85), Balthasar recuerda que "Platón lo llama de forma más razonable el "sol del bien" (86). Advierte, que "además no hay que olvidar que Pablo, lo mismo que Juan, piensa a partir del acontecimiento de la resurrección de Jesús, que contradice toda lógica y experiencia terrena... Así, estos entran desde un principio en la esfera de prodigio y desmesura que tienen ante sí, en la que uno ya no se puede orientar con una lógica terrena" (87).

Para Balthasar: "Un Dios se hizo hombre por amor al hombre: este acontecimiento es de tal inmensidad y tan contrapuesto a todo lo que la razón experimentó y lo que el ojo vio, que el hombre no puede responder a él con la palabra" (88). Se trata de un don de Dios, pues, “...quien ha recibido originariamente la gracia del lenguaje, se ve remitido por esta a la acción y así a la realización de la existencia lo mismo que a la de palabra misma, y todo ello en virtud de su raíz en el Logos" (89). Esto conlleva la pregunta de Tomás: “QQué es primero lógicamente: la relación o la procesión de las personas (processio)?" (90). Balthasar destaca el "ligero cambio" que Tomás introduce en la definición de persona de Boecio:”rationalis naturae substantia individua," afirmando "subsistens distinctum in natura rationali" (91). El teólogo suizo, subraya, entonces, el "subsistens in", que en Dios es un subsistir común de las hipóstasis en el único Esse subsistens de la esencia divina, hipóstasis que no se pueden distinguir de otro modo, salvo gracias a las "relaciones" determinadas mediante las "procesiones".

Ante este misterio trinitario al tratar la Posición del Logos en Dios, el autor afirma: "de este amor sin fundamento, que todo lo fundamenta, hay que decir inmediatamente que es cualquier cosa, menos ciego; al contrario, es lo más sabio y con ello el sentido último de todo saber y de toda razón (Vernunft); lo más recto, y por ello la orientación de todo lo que busca sentido y camino. Cuando en el eco munda-

(83) TL 2, 82-83(76): La analogía, sin duda, es uno de los aspectos más estudiados en la obra balthasariana, sobre todo, en su interrelación con los trascendentales y el amor, y recientemente también en su dimensión trinitaria, en cuanto analogia generationis. Cf. LUCIANI RIVERO R. F. o.c., $457-542$.

(84) TL 2, 87 (80)

(85) TL 2, 103 (95). Cf. LÖSEL S., Love Divine, All Loves Excelling: Balthasar'negative Theology of Revelation JR 82 (2002) 586-616.

(86) TL 2, 91 (84) (einsichtiger).

(87) TL 2, 106 (98).

(88) TL 2, 113 (105). Se trata de una cita de Piccard

(89) TL 2, 113s (106).

(90) TL 2, 129 (121).

(91) TL 2, 132 (123). 
no el hombre quiere conocer y saber para poder tomar la senda hacia una meta, lo que pone en camino es siempre el bien, que querría amar y que puede amar mediante su entendimiento" (92). Se abre aquí la profundidad definitiva del "sentido último de toda razón", puesta en camino orientada hacia esta meta con la plena convicción de que puede amar por su entendimiento.

Pero, continúa Balthasar, "el motivo es al mismo tiempo el contenido de lo que se comunica: lo que en el Logos es visible del Padre es una vez más el amor en todas sus dimensiones divinas, y por tanto, también con todas las consecuencias que de allí se derivan para una posible creación libre. Por consiguiente, si el Logos queda determinado en Dios como el lugar en el que se despliega una lógica divina, esta lógica -sin destruirse a sí misma como tal- solo puede ser designada como una lógica de amor. Ella expresa el amor del hontanar, que se derrama en ella, no solo como forma exterior, sino como su esencia íntima" (93). Tal argumentación balthasariana logra articular la comprensión genuina de cuanto entiende por "lógica de amor", aquel hontanar, cuyo desborde se hace visible en el Logos hecho carne.

Y lejos de interrumpir su análisis argumentativo, Balthasar vuelve a la pregunta inicial, insistiendo: "Aquí se puede encontrar una indicación para la posición de la lógica dentro de la estructura de la ciencia mundana. No es que pueda desempeñar en ella la misma función del centro, pero tampoco podrá aislarse de la estructura global del ser, lo mismo que una persona divina no puede desvincularse de las relaciones con las demás. También la lógica mundana tendrá su "desde", o sea la ontología en general, que (como la doctrina de la esencia divina es inseparable de las hipóstasis) no se puede apartar completamente de su concreción en los distintos ámbitos del ser y su "en referencia a", su función reguladora en ellos" (94). Esboza de este modo el autor así la posibilidad de una lógica de ciencia mundana trinitaria, en su concreción referencial y vinculante desde dentro.

Esto lo explica Balthasar, con más detenimiento, cuando practica una nueva vuelta al texto bíblico, insistiendo: "Si ambos conceptos, "Palabra" y "Espíritu", se entrelazan en la actividad divina y en la creación y la historia, su relación se oscurece aún más por la creciente independencia del concepto "Sabiduría". Lo importante aquí no es tanto su primera época, intensamente profana, especialmente su sensatez vital importada de Egipto, sino esos textos en los que se muestra por primera vez en calidad de la razón (bina, sinónimo de hokmah: Jb 28, 20; Pr 8,1) que habita en la creación de Dios, importante es que la primera obra de la creación... llama en voz alta por las calles ( $\operatorname{Pr} 1,20)$, hace su propio elogio ante ellos (Si 24,1), donde conceptos como justicia, rectitud, prudencia, conocimiento, reflexión, razón (Pr 2,9ss) describen su plenitud interior, y como la Palabra de Dios sale de la boca del Altísimo" (95).

Advierte el teólogo suizo: un tal "salir"... "no será armónico y neutral, como en Filón y en la concepción estoica del Logos, sino sumamente dramático, pues no estará acogido por la tiniebla que reina en el mundo. Tampoco es simplemente la

(92) TL 2, 139 (130).

(93) TL 2, $150(140-141)$.

(94) TL 2, 154 (144).

(95) TL 2, 156 (146). 
continuación de las numerosas palabras de Dios, ya pronunciadas en la historia salvífica de Israel. No es "palabra de Dios", sino simplemente "la Palabra", si se quiere traducir Logos en general con el término restrictivo "palabra". "Logos" involucra tanto "sentido" y "pensamiento" como palabra pronunciada" (96). Con esto se aprecia la gran finura de la argumentación balthasariana, esa síntesis de los aspectos "lógicos" más diversos, que dejan en claro su interelación con el sentido y el lenguaje, factores todos constitutivos tanto del sentido conceptual como del amor.

Finalmente Balthasar sugiere: "Para comprender más concretamente el concepto de Logos del prólogo, lo mejor es ponerlo junto a lo que al comienzo de este libro se dijo sobre el concepto de verdad: verdad se entiende aquí inequívocamente como la "explicación" o "exposición" (exégesis) de Dios Padre a través del Hijo, por lo cual la explicación que tiene lugar en la carne se remite sin duda al propium hipostático intratrinitario del Hijo. El hecho de que él, al explicar al Padre, explique a Dios, y no sin proporcionar el Espíritu Santo, demuestra que la "actividad exegética" no es una acción puramente económica, sino propia del Logos divino, coincidente con su esencia como "Palabra" e "Hijo" (97). Se percibe una conclusión significativa sobre lo propio hipostático intratrinitario del Hijo en cuanto fundamento de aquella lógica de amor que patentiza su concreción económica.

\section{d) La logicidad de la contradicción del amor divino}

Al oponerse a un enfoque unilateral de las procesiones divinas, Balthasar pregunta: "Cuando se dice que el Padre entrega a su Hijo por amor al mundo (Jn 3, 16), ¿se puede admitir que no ha generado al "Hijo de su amor" (Col 1,13) por amor, sino mediante un acto de conocimiento? Con ello, además, persiste el misterio insondable de si lo ha engendrado "necesariamente" (¿pero forzado por qué, si no es por el amor?), o "libremente" (¡pero ciertamente no a su capricho!). Esta prioridad del conocimiento respecto al amor ¿no sería algo traspasado del mundo creado al divino? ¿Y no se debe mantener esta prioridad en la doctrina sobre la Trinidad, a fin de poder distinguir las procesiones del Hijo y del Espíritu? ¿Acaso no sería posible diferenciar en Dios lo omnicomprensivo del amor (que contendría en sí todas sus demás propiedades divinas, incluidos el conocimiento, la omnisciencia, la sabiduría), de tal modo que, sin embargo, resultara visible cual fundamento para la distinción de ambas procesiones dentro del único amor divino?" (98).

Con estas preguntas pretende cuestionar a Tomás, aunque le da razón en cierto sentido, cuando afirma: “...se puede conceder con Tomás que entendimiento y voluntad no se distinguen realmente en Dios, que algo solo puede ser amado cuando es conocido, y, por lo tanto, se debe mantener un orden de las procesiones. Pero persiste la cuestión de si este tipo de orden no es leído en última instancia solo en la imago creada, y elevado desde allí a principio metafísico. Pues en la imago siempre se presupone, antes del intelecto y la voluntad, la sustancia que las sustenta, cuyo origen

(96) TL 2, 157 (157).

(97) TL 2, 158 (147-148).

(98) TL 2, 159-160 (149-150). 
una vez más solo puede ser la liberalitas divina, sin la cual (pese a la ejemplaridad creativa del Hijo) no podría haber creación alguna)" (99). Balthasar desacredita aquí una diferenciación entre entendimiento y voluntad, en cuanto yuxtapuestos.

Esta yuxtaposición le lleva a complementar a Tomás con Buenaventura, y a esclarecer la Diferencia trinitaria y diferencia del ser: ... Para Tomás, el atributo central de la segunda persona es Verbum, y en cuanto Palabra interior (verbum mentis) expresa el Padre que se conoce. Por el contrario, para Buenaventura, el atributo que compendia es "Expresión" (expressio), en el cual se sintetiza el sentido de los demás nombres" (100). Y el teólogo suizo agrega: "según Tomás la diferencia se encuentra primordialmente in intellectu, en el juicio del espíritu, pero este no podría juzgar si las cosas no se le abrieran en su verdad ontológica, como se mostró detenidamente acerca de la inseparabilidad y recíproca intensificación, de espontaneidad y receptividad, de "abstractio" y "conversio ad phantasmata", de captar y dejar ser, síntesis y análisis..." (101). Aquí se hace notar la innegable preferencia que Balthasar concede a Buenaventura, más allá de lo que Tomás le aporta.

De hecho, aclarando la Consumación desde Dios y referiéndose a Buenaventura, el teólogo suizo acentúa que este pensador "da aquí con el medium (meson), presentado por Aristóteles como ideal de virtud, un centro ciertamente justificado entre extremos, en el que, sin embargo, se muestra la total provisionalidad de las normas morales intramundanas. Dicho centro se encuentra a través de una "correcta planificación (recta ratio). Pero, si el hombre ha de elevarse por encima de sí mismo, para poder planificar rectamente con respecto a sí, debe abrazar la fe" (102). Emerge aquí el medium, aquel espacio intermedio entre los extremos, que constituye el centro planificado, recta ratio.

Recurriendo a Nicolás de Cusa, Balthasar explica: "Para el hombre, como quintaesencia del mundo... se concluye una oposición decisiva: por un lado, su razón (ratio), que construye sobre lo sensorial, no puede conocer ninguna cosa mundana tan exactamente (praecise) como es en sí, porque todo su saber mundano y su ser construido sobre éste... sigue siendo "conjetural” (103). Y continúa:"Con lo cual, sin embargo, no se puede pasar por alto que el hombre es un ser finitamente subsistente, mientras el acto de ser al que su razón se asimila (anima quoddammodo omnia) no subsiste como tal" (104). Balthasar rescata aquí el actus essendi, que desde Tomás no tiene subsistencia, pero deja existir a otro (105).

Lo cual deja en claro que "El acto de mirar es la manifestación de los colores y las formas. Lo que llamamos sentido es tanto nuestra capacidad como el significado de las cosas. La palabra mirar (blicken) significa originariamente lo mismo que

(99) TL 2, $161(150)$.

(100) TL 2, 162 (152): Cf. PESARCHICK R., The trinitarian foundation of human sexuality as revealed by Christ according to Hans Urs von Balthasar. The Revelatory significance of male Christ and the male ministerial Prieshood (Tesis gregoriana, Serie Teológica, 63) Roma 2000, 323 pp.

(101) TL 2, 178 (168).

(102) TL 2, 193 (182).

(103) TL 2, 204 (192-193).

(104) TL 2, 222 (209).

(105) Cf. LAMBINET J., Das Sein als Gleichnis und der Mensch als Bildnis Gottes, en REIFENBERG P., VAN HOOFF A., (eds) o. c., 184-209. 
“destellar"(blinken). Sentir (empfinden) quiere decir, evidentemente, tomar una cosa, sacada de lo simplemente encontrado (finden) en lo íntimo de la sensación. Lo que se construye en las cosas a partir de elementos, y se ha creado como "formación", se vacía como expresión en el sentido que, a su vez, se vacía en el mundo, y con la imaginación es llevado por este a la memoria, que lo puede reproducir. En tal proceso coopera ya el espíritu, que, al comprender la imagen desplegada, sensiblemente recoge (logos de legein, recoger) y lo que es más importante todavía, refiere la imagen (como "manifestación de...") al ente, que se representa en ella de forma plástica" (106).

Una vez abordada la amplia gama de la Lógica Divina, que se refleja en la mundana, Balthasar hace entrar su argumentación en la fase final, cuando profundiza: "Si denominamos a su portador "el Logos", y, a esta túnica, Lógica, ningun otro camino tiene perspectivas de éxito sino el que parte del presupuesto de esta inconsutilidad. Puesto que el Logos se denomina también la verdad, no hay verdad inconsútil como su explicación de Dios, explicación de Dios Padre en el Espíritu Santo, la cual es al mismo tiempo la exactitud más manifiesta y el misterio más profundo..." (107).

Significación que Balthasar reafirma en su Conclusión: "Esta verdad es ante todo la explicación del Dios Uno y Trino, que para la miope lógica mundana parece ya una primera contradicción, porque dicha lógica deja de lado el amor, que solo puede alentar más allá de uno, dos y tres. Pero esta verdad es igualmente la explicación del mundo pecaminoso y alejado de Dios, lo que es en la cruz y el infierno, cuya unidad se mofa de la lógica humana casi más aún que la explicación de Dios. Pues de la cruz entiende la lógica humana tan poco que, ni puede entender cómo uno puede cargar con el pecado de otro, o incluso de todos (Kant ha explicado suficientemente este contrasentido), ni cómo el incomprensible abandono del Hijo por parte del Padre puede ser un acontecimiento que afecta a la Trinidad misma de Dios, ni cómo este envento puede abarcar todos los tiempos pasados y futuros... ni cómo la manifiesta contradicción del pecado, frente a la verdad de Dios, puede ser vivida y hasta superada internamente" (108).

Por todo lo cual, el teólogo suizo subraya: "En esta doble explicación simultánea de cielo e infierno se hace pedazos toda especulación humana, y el intento de montar, pese a todo, algo así como un sistema de verdad... Pero el que se define como camino y la verdad, es lo contrario; y por eso ha corroborado el principio hegeliano de que todo lo racional es real, y todo lo real racional... se define por un camino completamente diferente... de una manera que Pablo llama la locura de Dios, que es más sabia que la sabiduría de los hombres... (109). Puede apreciarse aquí la radicalidad de la Lógica de Dios, en cuanto amor desinteresado y sin fondo, contrapuesto a la astucia egoísta de la lógica hegeliana.

(106) TL 2, 243 (230).

(107) TL 2, 349 (330).

(108) TL 2, 349 (330).

(109) TL 2, 350 (330-331): Cf. STINGLHAMMER H., Freiheit als Hingabe. Trinitarische Freiheitslehre bei Hans Urs von Balthasar. Ein Beitrag zur Rezeption der Theodramatik (Bonner Dogmatische Studien, 24) Würzburg 1997, 37ss. 
Advierte Balthasar: "Esta locura no se revela en la esencia de Dios... sino en Aquel que en un acto único supo unir lo absolutamente divino y lo absolutamente antidivino, no en una locura de un gesto titánico sobrehumano, sino en la sencillez de su obediencia. Solo esta obediencia explica a Dios como el amor trinitario y lo hace precisamente por el hecho de que el Padre, por amor al mundo, entrega a su Hijo a la contradicción de lo antidivino. Cruz y trinidad se demuestran recíprocamente, por lo cual la cruz es asumida en todas sus dimensiones antes mencionadas, incomprensibles para la lógica humana..." (110). La argumentación balthasariana toca el fondo de la logicidad de un amor extremo, cuya comprensión es inalcanzable para cualquier lógica humana, en tanto el mismo Espíritu de la Verdad no nos introduzca en ella con una inteligencia nueva, es decir, regalando su comprensión.

\section{3) LÓGICA Y AMOR EN EL ESPÍRITU DE LA VERDAD.}

La cuestión básica de la tercera parte de la Trilogía, Espíritu de la Verdad, es más escueta, pero igualmente contundente, pues el autor pregunta ya en el Preludio: “CCómo llega el Espíritu a la lógica?” (111). A primera vista, parece tratarse de factores desconectados e irreconciliables. Sin embargo, "Espíritu” y "lógica" se interrelacionan, de hecho, íntimamente, como lo permitirá apreciar la alteración, que el autor lleva nuevamente a cabo en el campo semántico de la racionalidad. En efecto, dicha racionalidad se perfilará a través de los vocablos "inteligencia" (Einsicht) y "comprensión” (Verständ-nis) en su relación con el amor.

\section{a) La cuestión de la presencia del Espíritu Santo en la lógica}

Balthasar reconoce en el Prólogo: "la dificultad de este tomo, que concluye la Teológica, estriba en mantener -dentro de los límites impuestos por el tema (la lógica) - la sobreabundancia de lo que habría que decir sobre el Espíritu Santo" (112), pues la pregunta ¿cómo llega el Espíritu a la lógica? involucra el hecho que: "El destino global del Espíritu es la explicación introductoria... Como ha quedado indicado, el Hijo, en cuanto encarnado, era la adecuada explicación del Padre; pero dicha explicación seguía siendo un ámbito cerrado para los hombres, mientras no viniera el Espíritu" (113).

Por eso, el teólogo suizo al preguntar ¿Es posible una teología del Espíritu Santo?, advierte que tal teología “...debe de haberse situado ya dentro de este acontecimiento de la Palabra, pues las palabras del Hijo (y todo en Él era palabra) eran ya "espíritu y vida" $(6,63)$. Esta relación inseparable de Logos y Espíritu en el acontecimiento de la Revelación se ha de demostrar detalladamente... en ningún modo significa que el Espíritu se limite a explicar una doctrina (ni siquiera la letra de la "Escritura"); más bien introducirá en las profundidades vivas del acontecer

(110) TL 2, 350 (330-331).

(111) TL 3, 19: Verständnis, que da el Espíritu Santo (XXII)

(112) TL 3, 13 (9).

(113) TL 3, 19 (13). 
entre el Padre y el Hijo, del ámbito hipóstatico" (114). Resulta decisivo que la acción del Espíritu no se limite al nivel teórico, sino involucre tanto el ámbito hipostático, como eclesial.

Esto significa que, "En primer lugar la introducción del hombre eclesial en el ámbito de la verdad intradivina se puede explicar principalmente como transformación en el ámbito de Dios. En segundo lugar, la acción del Espíritu será susceptible de dos líneas de interpretación: en una se entenderá más como purificación, iluminación, unificación, divinización, efectuada mediante el entendimiento y también la virtud (así, los Padres griegos); en la otra se puede interpretar más como incorporación al cuerpo de Cristo" (115). Pero "la Antigua y, con mayor razón, la Nueva Alianza no descansan en sí mismas, sino que están abiertas de forma misionera a todos los pueblos; y, lo mismo que entre ellos existe un logos spermatikos, así también debe de haber entre ellos algo así como un pneuma spermatikon” (116). Aquí se abre aquella amplitud del Espíritu, presente en el mundo, que acusa la interrelación entre conocimiento y amor.

Pues "Lo que sucede, más bien, es que se manifiestan continuamente nuevos panoramas sobre la totalidad infinita; no vagas, sino determinadas visiones que pueden ser conocidas o vividas más intelectual o más amorosamente" (117). Es decir, "se trata, en todos los casos, de carismas en los que inteligencia, amor y seguimiento son inseparables. Se puede percibir que el Espíritu-explicador es a la vez amor divino y sabiduría divina; en modo alguno, pura teoría, sino siempre praxis viva también" (118). Se da aquí una alternativa significativa entre el conocimiento más intelectual o más amoroso, que, sobrepasando la teoría pura, confluye en la unidad de la "praxis viva".

Balthasar remonta tal unidad a la dimensión trinitaria, cuando constata: "Desde aquí resulta posible una primera ojeada previa a la forma esencial de la teología cristiana. El Dios “desconocido", el Espíritu, arroja su luz sobre el Dios “conocido", el encarnado, para esclarecer su significado como intérprete del Padre invisible (y por tanto, ."desconocido"). Solo en cuanto el Hijo es reconocido como intérprete del Padre como del "otro" (Jn 5, 32), con quien Él no obstante "es uno" (Jn 10, 30) también es entendido como la verdad (Jn 14,6) y con ello se comprende su verdad (o Él en la verdad)" (119). Emerge aquí la misma dualidad encontrada en la Verdad del mundo respecto de "lo conocido" y "desconocido", pero ahora especificada en su expresión trinitaria hipostática.

Tal expresión permite apreciar: "Donde el Espíritu arroja su luz, a la vez está con ello la diferencia y la identidad entre Padre e Hijo: la unidad de diferencia e identidad será vista simultáneamente, pero no comprendida; de esa manera, mediante la interpretación del Espíritu, en el Encarnado se manifiesta al unísono algo comprensible y algo incomprensible. Lo comprensible también ha de poder ser conocido hasta

(114) TL 3, 20 (13)

(115) TL 3, 21 (15): Einsicht.

(116) TL 3, 22 (16): Gs 22 rescata esta verdad en profundidad.

(117) TL 3, 23 (16)(Einsicht).

(118) TL 3, 23 (17).

(119) TL 3, 30 (24). 
cierto punto por la inteligencia natural del hombre" (120). Surgen de este modo la diferencia e identidad al interior de la Trinidad, y su visión simultanéa que, sin ser totalmente comprensible para la inteligencia natural, en algo es conocida por ella a la luz de la inversión desproporcional, que invoca la argumentación balthasariana.

Lo anterior significa que "El Espíritu iluminador (como lux beatissima) al tomar posesión de todo el espíritu permite que se haga teología (cordis intima); a través de su Misterio, permite obtener una inteligencia (Ein-sicht) del misterio del Hijo que interpreta al Padre, inteligencia de Él y de su relación con el Padre... Así, la teología liberal, que se tiene por sabia, pero en realidad es necedad, es llevada adelante hasta la inteligencia "de una sabiduría de Dios, misteriosa, escondida"... Dicha sabiduría... que Pablo en numerosas descripciones presenta como conocimiento de lo que está por encima de todo conocimiento (cf. Ef 3, 19), o conocer "como soy conocido" (1Co 13, 12), o movimiento hacia el "conocer en el ser, ya conocido (1Co 8, 3; Flp 3, 12)" (121). Resalta aquí una comprensión dual, que Balthasar destaca como Ein-sicht, es decir, intelección que coincide no solo en el Padre e Hijo y como tal se sobrepasará a sí mismo en cuanto visiónuna, dado que también fruto del ser "conocido".

Tal posibilidad de "conocer" por "ser conocido", "se presenta... como un verse abrumado por el exceso de lo cognoscible. Por lo tanto, dicha sabiduría no puede llamarse ni apofática ni katafática, ni en esta vida ni en la eterna, donde conoceremos y veremos a Dios a través de Dios mismo, pero de una manera que no podrá ser global. Esto no significa que Dios nos oculte algo de sí, sino al contrario: conforme a su esencia, da siempre más de lo que podemos comprender" (122). "Todo esto es para el teólogo la obra interpretadora del Espíritu Santo, quien, dando de esta manera conocimiento del Hijo y el Padre, también lo concede sobre sí mismo, en cuanto es la exuberancia propia de Dios" (123). Resulta clave el exceso de lo cognoscible, no simplemente originado por los límites de la razón, sino en cuanto proveniente de aquella plenitud siempre mayor, que es propia del Dios-Amor. ¿Pero también para Sí y en Sí mismo hay exceso?

\section{b) El Deus semper mayor para Dios mismo}

Balthasar argumenta en sus Aproximaciones: "Si se parte de lo dicho inicialmente sobre el Espíritu de Dios, de forma global y no totalmente indiferenciada se podrá afirmar del Espíritu que es aquello a través de lo cual Dios se da a conocer como Dios, ante lo no divino" (124)... "Para situar correctamente esta afirmación, una vez más es necesaria una reflexión retrospectiva sobre el punto de partida joánico en $T L$ 2... Jn 14, 6" (125). Se aprecia la estrecha interrelación entre Logos y Espíritu, decisiva para la comprensión del discípulo.

(120) TL 3, 30 (24) (Einsicht).

(121) TL 3, 32 (25): Ein-sicht, dos veces.

(122) Balthasar cita aquí a J. Pieper, quien habla de la "luz que no se puede beber hasta el fondo" (2. 1963), lo cual significa: hay tanta luz, que, dada una facultad comprensiva finita, no se es capaz de beberla hasta el fondo; se sustrae a la aprehensión conceptual"(32).

(123) TL 3, 32 (26).

(124) TL 3, 65 (57).

(125) TL 3, 71 (61): Verständnis. 
El autor explica en su Retrospectiva el "testimonio mayor que el Padre ha testimoniado acerca de su Hijo (1 Jn 5, 6-9)" (126), cuando subraya: "el obsequiado penetra realmente en la esfera trinitaria, que comunica una inteligencia desde dentro. Los discípulos solo entienden después de Pascua..." (127), Y continúa: "si no fuera derramado en nuestros corazones, sin haber bebido de él $(1 \mathrm{Co} 12,13)$ nunca habríamos llegado ni a la comprensión de la verdad divina ni a poder vivir dentro de dicha verdad" (128). Respecto de la comprensión, el autor acota: "pues el Espíritu se muestra aquí, no solo como introductor, sino manifiestamente como el "explicador"... Pero con ello se ha dado el paso del Espíritu, como "explicador" de la verdad, al Espíritu como "introductor" en la vida según dicha verdad, lo único que proporciona verdadera comprensión” (129). Confluyen así en el Espíritu y por medio de él la comprensión trinitaria con el entendimiento natural del discípulo.

Debido a ello, y, refiriéndose al "carisma de la profecía", advierte Balthasar: "La verdadera obra del Espíritu en el hombre consiste en... llevarlo precisamente, mediante la inclusión de su pensamiento y entendimiento natural, al pleno conocimiento, saber y entender" (130). No se trata, pues, de una "fuerza impersonal..., un Padre que no tiene otra cosa que un Hijo. Esto produce una imagen de Dios inconcebible para el intelecto humano, y también incaptable según lo que muestran las imágenes trinitatis..." (131). Emerge aquel espacio entre el Padre y el Hijo, en el cual el entendimiento humano es realmente introducido por ser "imagen de la Trinidad".

El teólogo suizo aborda al Espíritu Santo como persona, y se distancia de Agustín y su imago trinitatis in mente, cuando observa: “...según esta imago, el Logos es engendrado y hecho persona bajo el signo del entendimiento, mientras el Espíritu procede bajo el signo de la voluntad, de la liberalitas (Buenaventura), del amor...". Todo lo cual significa: "Por un lado, la entrega del Hijo por parte del Padre no se puede valorar de otro modo que como su donum supremo al mundo. Con ello, tampoco la generación intradivina del Hijo puede ser entendida de otro modo, que como un acto del amor absoluto (vimos en el TL 2 que el Padre no puede engendrar al Hijo para conocerse, pero tampoco porque se conozca)" (132). Aboga el autor en favor de que todo el acontecimiento trinitario inmanente sea comprendido como donación, dado a conocer en la economía por el Espíritu.

Para mayor razón, continúa: “....absolutamente toda la obra económica del Espíritu se describe como una obra de "comprensión" de cuanto el Padre nos ha otorgado en el Hijo. Y toda la "introducción” a la naturaleza divina, y también todo lo que en la escuela de Bernardo se describe como el sapere, sentire, praegustare otorgado por el Espíritu (como saborear y experimentar las cosas desde dentro), está claramente al servicio de la "guía hasta la verdad completa" (Jn 16, 13)... Lo confirma la conexión continuamente destacada por la Edad Media entre este sapere amo-

(126) TL 3, 85 (74): Verständnis.

(127) TL 3, 85 (74): Verständnis.

(128) TL 3, 88 (77).

(129) TL 3, 89 (78).

(130) TL 3, 90 (78).

(131) TL 3,117 (104).

(132) TL 3, 141 (127): Erkenntnis. 
roso y la sapientia, la única que realmente entiende; conexión que constituye la determinación fundamental de la teología" (133). El entendimiento, originado por el Espíritu, entonces, conlleva un "saborear amoroso", que atestigua que el conocimiento y el amor se compenetran y no se yuxtaponen, como parece sugerir el enfoque agustiniano.

En efecto, insiste el teólogo suizo: "esta época, que formalmente creía tener que atenerse absolutamente a la imago agustiniana y sus consecuencias trinitarias, es llevada por sí misma más allá de su punto de vista. Esto queda también claro en toda la problemática (debatida entre Buenaventura y Tomás) del primado del conocimiento y del amor. Pues los siete dones del Espíritu Santo, tan genialmente dispuestos por Tomás, sirven todos, según él, para inspirar en nuestras facultades cognoscitivas un instinctus de amor divino que ha de asimilarnos interiormente al Misterio, mediante los misterios de fe y nuestra conducta de fe. Por su parte, el excesssus del amor, según Buenaventura, no deja atrasada al entendimiento, sino que significa al mismo tiempo la forma más alta de intelligentia” (134). En cambio, para Hegel, "la razón puesta en libertad, habría podido seguir en este momento sus propios preceptos..." (135). No cabe duda que hasta el instinto y exceso del amor conlleva conocimiento e inteligencia, un hecho desconocido por Hegel.

Balthasar avanza un paso más hacia una mayor originalidad, cuando advierte: "Si Dios es ya desde el principio en el Padre el milagro del amor, ser Él mismo en la entrega, este milagro se realiza en el Espíritu Santo, que, precisamente en cuanto exuberancia del amor, en su "ser siempre más", es la cumbre incomprensible e insuperable del amor absoluto. Deus semper major no solo para nosotros, sino para Dios mismo. Pero nada de embriaguez dionisíaca, sino la sobria ebrietas del Dios que en los tres modos de poseer personalmente la única esencia divina participa de todas las propiedades divinas: perfecto conocimiento, omnipotencia, justicia, santidad, beatitud,..." (136). El Espíritu Santo constituye, entonces, la "cumbre incomprensible e insuperable del amor absoluto", pero también la plenitud del perfecto conocimiento, siendo a la vez nexo y fruto del amor del Padre y del Hijo.

\section{c) La lógica del amor en la unidad del Espíritu en cuanto nexo y fruto}

Para Balthasar no existe otra posibilidad de aproximarse al Espíritu Santo, salvo "desde dos lados - como quintaesencia (subjetiva) del amor recíproco de Padre e Hijo, del que aparece como vínculo (nexus) y como fruto (objetivo) nacido de este amor, que lo testimonia-", lo cual significa "un recíproco ir al encuentro de ambos polos" (137). Por eso, el autor concluye: "El Hijo en modo alguno revela económicamente al Padre solo per modum intellectus, sino que, como comprueba suficientemente Juan, a través de su amor absoluto al Padre y a los hombres como amados por

(133) TL 3,141 (128).

(134) TL 3,142 (128).

(135) TL 3, 154 (139).

(136) TL 3, 161s (146).

(137) TL 3, 163ss (146): Resulta sugerente el ejemplo del embarazo: "se pudiera eliminar mentalmente, del acto de amor entre hombre y mujer, los nueve meses de embarazo..." 
el Padre, revela primordialmente el amor del Padre. En este sentido, el Espíritu debería llamarse donum doni..." (138).

Y prosigue: "la autoexpresión del Padre en el Hijo, ciertamente, no es indiferente, sino afirmativa y amorosa en sumo grado. Mas según Agustín, el amor se encuentra ya por entero en la generatio Verbi, esta es cum amore notitia, de manera que en esta primera procesión en Dios ya parece encontrarse toda la circumincessio de conocimiento y amor, mediante la cual también el envío del Hijo al mundo por parte del Padre acontece en el amor, y es llevada a cabo por el Hijo en el amor: lo cual en principio podría presentar el papel del Espíritu como superfluo en apariencia. La verdad, que se encuentra en el Hijo, ya es amada como tal" (139). La circumincessio de conocimiento y amor alcanza aquí su punto culminante en aquella compenetración, que se ha ido preparando. Tal índole "superflua" del Espíritu, sin embargo, pone de relieve aquel despojamiento en el cual participa el Espíritu del mismo modo como el Hijo, y que como tal, recuerda el sentido del ser propiamente dicho.

Efectivamente, en los Distintivos del Espíritu Santo el teólogo suizo afirma: "En el despojamiento del ser como don del amor se revela el necesario sentido del ser. En él se legitima dicho sentido, por cuanto es el éter del despojamiento, su elemento vital y el poder que lo alienta"... Ya hemos tratado precisamente del silencio de la Palabra en el Padre ante la inefabilidad de la maravilla del Espíritu, y de que el Espíritu puede así ser llamado "el desconocido más allá de la Palabra”. Pues bien: "el Espíritu comienza a explicar interminablemente la Palabra, que ha ido "hasta el extremo", precisamente allí donde esta enmudece en la muerte...y con este enmudecer expresa todo el amor del Padre..." (140). Ese "sentido", entonces, concreta la sensibilidad de la razón convertida en amor, sensibilidad que evoca el Espíritu en cuanto"desconocido más allá de la Palabra".

Todo ello le induce a esa advertencia: "La teología debería guardarse de racionalizar (logisieren) este misterio del Espíritu, y de acabar materializándolo mediante distinciones sin fin, que no aportan nada a su iluminación" (141). "Por eso, el condilectus reclamado para la abnegación por Ricardo de S. Víctor, no se puede poner como un tercero aparte del amor recíproco de los dos amantes, sino como uno solo que surge de la lógica interna del mismo amor abnegado. Él es la quintaesencia resultante del amor divino, que, como su fruto último, representa el producto de una voluntad de necesidad del Padre y de una voluntad del Hijo formada de la necesidad del Padre, y, a la vez, libertad" (142). Resalta aquí la abnegación del condilector, cual la lógica interna del amor propiamente tal.

Y el teólogo suizo resalta esta significación: "Lo importante es retener la unidad de ambos aspectos de la misma hipóstasis del Espíritu: en cuanto fuego más íntimo del amor de Padre e Hijo, es el conocimiento absoluto del amor desde dentro; pero, en cuanto producto, fruto de este amor, es simultáneamente -como amor- el testimonio objetivo de que este amor tiene lugar eternamente (el niño, testimonio de

(138) TL 3, 164 (149)

(139) TL 3, 222 (204).

(140) TL 3, 228 (210).

(141) TL 3, 231 (231).

(142) TL 3, 237 (218). 
un acto de amor de los padres, que ha tenido lugar en el tiempo, es solo una pálida réplica de aquel)" (143). Puede apreciarse, de este modo, la simultaneidad de los aspectos subjetivos y objetivos que asume la explicación pneumatológica de esta compenetración, donde se fusionan conocimiento y amor, cuya "imagen pálida del niño" está tomada de Scheeben.

Balthasar no cesa en su insistencia: "Aun cuando en Dios hablar de subjetivo y objetivo en última instancia está fuera de lugar, sin embargo, en la "lógica del amor" los dos aspectos del Espíritu se pueden distinguir; pero, en contraste con Hegel, no como momentos de la autorrealización del Espíritu absoluto, sino precisamente en su eterno ser realizado. Y desde el extremo también se hacen después distinguibles (no separables) dentro de la obra económica de la Trinidad: no como momentos de un conocimiento absoluto que deviene, como en Hegel, sino como momentos (en parte realmente temporales) del amor absoluto que se llevan adelante en el devenir del mundo" (144). Con tal acotación, respecto de la postura de Hegel, se explicita mejor la originalidad y mayor nitidez de la interpretación balthasariana de la "lógica del amor".

Y remata su argumentación, "El hecho de que el Espíritu aparezca claramente como el explicador definitivo de la "lógica" divina, debiera deducirse del conjunto: en cuanto amor entre Padre e Hijo, y ya con ello como su don mutuo, él es al mismo tiempo su fruto, con lo cual este amor queda simultáneamente liberado para la libre donación. En este doble aspecto, el Espíritu es, por decirlo así, explicador de sí mismo; pero solo en cuanto se explica como el amor mutuo de las dos primeras personas, y además su revelación completa (en el envío del Hijo por el Padre, hacia la cruz). Y pese a que, para esta explicación suya se emplean palabras como "enseñar", explicar", introducir, testimoniar, convencer, no realiza todo esto verbalmente (como corresponde al Logos), sino por medio de la comprensión vinculada con el amor mediante su unción (1 Jn 2, 27), que otorga una gnosis como no puede transmitirla ninguna enseñanza verbal" (145).

No obstante lo anterior, concluye "la libertad del Logos exaltado nunca se puede contraponer, ni tampoco yuxtaponer simplemente a la libertad del Espíritu Santo" (146). Puede apreciarse aquí la distinción y complementación de la fundamentación trinitaria del problema razón y amor en la complejidad de sus ejes, que conlleva el exceso como última explicación de la kenosis, en cuanto característica más específica de lo cristiano (147).

\section{d) El exceso de la caridad con respecto al conocimiento}

Balthasar, al ahondar la Teológica, encamina su argumentación hacia la fase final: "hay que admitir que a Dios solo se le puede entender a través de Dios; pero con ello todavía queda por reflexionar el hecho de que, "entender" es un acto del

(143) TL 3, 242 (224).

(144) TL 3, 243 (225): Logik der Liebe.

(145) TL 3, 294 (272).

(146) TL 3, 295 (273).

(147) TL 3 298: Balthasar cita a KOBUSCH Th., Freiheit und Tod. Die Tradition der mors mystica und ihre Vollendung in Hegels Philosophie, TQ (1984) 185-203, aquí 187. 
hombre como tal. El entender humano comienza cuando yo soy interpelado por un tú, es decir, por una libertad ajena que, advirtiéndome de un determinado estado de cosas, me hace estar atento. Aunque de ese modo no se realiza simplemente dicho estado de cosas... se deja constatar como significativo, correcto, verdadero" (148). Vuelve el autor, entonces, una vez más "desde Dios” al entender humano, que evoca aquí como acontecimiento intersubjetivo y como tal posible a través del lenguaje.

Balthasar acota: "El lenguaje siempre actividad indicativa que señala algo, solo acontece -también en cada diálogo- dentro de dos ámbitos: uno es la comunión de un horizonte de comprensión del sentido (prelinguístico) en general, que abarca a ambos; el otro, es la libertad nunca demostrable de cada hablante, al que cada vez se debe "creer" lo que manifiesta, aun cuando bastante a menudo dé pruebas empíricas de su exactitud. A esta libertad, que se expresa, tiene que dar las gracias siempre el interpelado (149). Insiste el autor en aquellos aspectos de la comprensión lingüística, que dan certeza, solo en la medida en que son creídos, de modo inteligente.

Balthasar postula tal certeza inteligente también para los momentos de éxtasis, que "pueden ser fructífero para el espíritu del hombre, que con ellos queda inmerso en profundidades de la oración que, como hombre común, nunca hubiera sospechado; pero estás profundidades también deben ser fructíferas para su vida apostólica práctica. "La mente" ha de tener parte en ello. Oraré con el espíritu, pero oraré también con la mente" (1 Co 14, 15)". El Espíritu, que necesita su exclusividad, no puede, sin embargo, renunciar al entendimiento" (150). Aquí Balthasar se hace cargo de la tradición paulina, que en ningún momento renuncia a la inteligibilidad por muy fuerte que sea la experiencia amorosa.

A ello se remite el teólogo suizo: "El puente se encuentra en la voluntad del hombre, que en la fe se somete a la voluntad de Dios y de este modo hace también dócil la voluntad humana. Mediante su obediencia, el hombre también es capaz de garantizar al Espíritu Santo la aptitud de su entendimiento, en cuanto que la contemplación pura a través de la obediencia asegure la posibilidad de la acción, y solo mediante esta llegue a ser plenamente lo que Dios quiere: un bien para todos... El hombre debe orar hasta que el entendimiento quede tan captado por el Espíritu, que prosiga como hermano gemelo al Espíritu hasta donde este sea requerido..." (151). La insistencia en el entendimiento para la oración, garantiza la autenticidad de dicha comunicación con Dios.

Por eso, prosigue el autor: "si, en el instante en que habla con Dios, se lleva así mismo, trasplanta las cosas a su yo racional sin por eso pretender minimizar al Espíritu, entonces su razón toma parte en el Espíritu ...Pero como ya se ha dicho a proposito de la 'teología': hasta el hablar más racional sobre lo divino, dentro de la Iglesia puede resultar frúctifero solo si procede de la oración o, lo que es lo mismo, de la esfera del Espíritu Santo" (152). Advierte Balthasar: "La afirmación (1 Cor 2,

(148) TL 3, 356 (331) (Verstehen).

(149) TL 3, 356 (332).

(150) TL 3, 371 (346) (Verstand).

(151) TL 3, 371 (347) : Cita de A. von Speier (Vernunft).

(152) TL 3, 372 (347) (vernünftiges Ich) (Vernunft) (vernünftiges Sprechen). 
10) es sorprendente, porque el Espíritu mismo es Dios. Si se sondea debe a Sí mismo buscar en su propia hondura y reconocer que Él, que es el amor, se debe al amor, ante todo (principaliter) al amor de este origen insondable que lleva el nombre de Padre, y después al Amor del Amado, que puede agradecer el amor del origen amando con la misma fuerza. El Espíritu, que sondea estas profundidades, lo hace como testigo y fruto de este amor recíproco, ante el que, sin embargo, no se sitúa como observador, sino como Quien debe entenderse a Sí mismo" (153).

En procura de avanzar en su argumentación, el teólogo suizo evoca una vez más "la teología espiritual de la Edad Media, apoyada en la afirmación de Gregorio Magno... "el amor mismo es conocimiento". "El amor tiene su evidencia última en sí mismo, de la que deriva toda evidencia científica" (154). Agrega Balthasar: "Solo ahora queda claro que lo impensable de antemano del amor, que comienza en el acto de ser del Padre, no es nada irracional, ante lo cual el investigador debe resignarse y contentarse con una teología puramente apofática... (Rm 11, 33)": Si se traduce "irrastreable" o "impenetrable" suena como una invitación a dejar de lado la ulterior investigación; la teología se rinde. Pero esto contradice abiertamente la primera afirmación, que se arrodilla asombrada ante la riqueza de la sabiduría y del conocimiento (gnosis) de Dios (155). La actividad de la razón humana, sin duda, no cesa ni en los o momentos de mayor plenitud.

Aquí emerge para Balthasar algo así como una contradición con "la invitación de la carta a los Efesios: el cristiano "con todos los santos" puede intentar comprender (gnonai) (las dimensiones) del amor de Cristo, que excede todo conocimiento, para que se vaya llenando hasta la total plenitud de Dios (Ef 3, 18s)". Pero Balthasar explica : “...solo puede tratarse -junto con el Espíritu escrutador- de una penetración siempre interminablemente más profunda, que solo tiene éxito en el amor, en el milagro del amor sin fundamento del Padre -y del Hijo y del Espíritu, que dimanan de dicho amor-, amor que como tal, es ofrecerse a la gnosis indagadora o sabiduría (156). El "exceder todo conocimiento", entonces, se origina en el amor de Dios sin fondo, y apunta a Él.

Balthasar concluye: "conocer el amor que excede todo conocimiento (Ef 3, 19) es una paradoja solo en apariencia, pues el amor se ofrece a sí mismo al conocimiento. Desde luego, no al conocimiento que se encierra en sus propios principios, sino a aquel que se mantiene abierto al milagro del amor que mana eternamente, sin fundamento desde sí mismo. Gregorio de Nisa lo ha comprendido, y también formulado perfectamente. En vista de esta comprensión cristiana del origen paterno, resulta comprensible todo el comportamiento de Jesús: es una única referencia al Padre" (157). La confluencia de razón y amor se evidencia, entonces, en la praxis, es decir, se articula dinámicamente en la persona concreta, inmersa en el "milagro del amor" eterno.

(153) TL 3, 437 (405).

(154) TL 3, 438 (406).

(155) TL 3, 438 (406).

(156) TL 3, 438-439 (407).

(157) TL 3, 438-439 (407). 
Esto lo explica Balthasar a través de Tomás de Aquino, cuando dice que "debemos participar inmediatamente de la esencia divina, para poderla ver. Y, sin embargo, el mismo Tomás dice que los santos ven a Dios como infinitum, sed non infinite cognoscibilis est. Pero inmediatamente añade -en perfecta sintonía con los Padres de la Iglesia del siglo IV- que, si ver y entender significa abarcar (includere), sic nullo modo Deus comprehenditur,... cum sit infinitus. Un amor infinito no se deja comprender, pero cuanto más amor se tiene, más se puede penetrar en lo incomprensible; plus autem participabit lumine gloriae, que plus habet de caritaté... pero quien mora en la luz, y en ella lo ve y lo entiende todo, no necesita mirar al abismo del hontanar de la luz (158). En efecto, estar sumergido en este hontanar significa participar en El Infinito, de modo finito.

Por eso, en la parte final denominada El Padre invisible, Balthasar invita a quedar con la afirmación: "a través de la gloria del Hijo vemos aparecer el abismo de la gloria de amor del Padre invisible, y esto en la figura doble del Espíritu Santo del amor. Al mismo tiempo, nosotros, como nacidos del Espíritu, existimos en el fuego del amor, en el que Padre e Hijo se encuentran y por ellos somos también simultáneamente, junto con el Espíritu, los testigos y glorificadores de este amor" (159). La visión del Padre invisible a través del Hijo en la figura doble del Espíritu, entonces, hace confluir definitivamente el conocimiento y el amor en la simultaneidad de un amor, conocido siempre de nuevo.

\section{A MODO DE CONCLUSIÓN}

La novedad de la respuesta balthasariana al antíquisimo problema que presenta la relación Razón y Amor, se origina en la radicalidad con que el teólogo suizo remonta la condición de posibilidad de la razón al amor, sin fondo y trinitario, amor que a modo de un sempiterno hontanar se proyecta en cuanto verdad en la belleza y bondad de todo lo que es, vale decir, en los trascendentales del ser, constituyendo dicho amor, en términos ulricheanos, el trascendental por excelencia. El ser, entonces, proporciona a la razón aquel nexo, que la interrelaciona connaturalmente con el amor. Por consiguiente, el dilema de la razón pierde su vigencia en cuanto ella se encuentra inmersa en el ser, su "sentido último", es decir, en donde "los sentidos" le permiten captar a partir del ente singular concreto existente, que tal existencia se abre a la vez sobre el trasfondo de la totalidad englobante, el "sentido", en cuanto última certeza racional querida y amorosamente entendida.

Proceso tal, verificado por el descubrimiento de la dualidad "existencia y esencia", con las subsiguientes diferencias, al interior del ser mismo, gracias a la interpretación controvertida que ofrece Sierwerth del actus essendi tomaseano, y que Balthasar hace suya con una impresionante visión de futuro, si se piensa en lo que actualmente se discute a nivel filosófico. Pues, por no tener subsistencia, el ser es totalmente misérrimo, aunque posibilitado por la existencia de todo cuanto existe;

(158) TL 3, 444 (410) (fassen) (Unfassliches).

(159) TL 3, 444 (410). 
no es Dios, sino su imagen por excelencia. Pues, debido al gesto básico de dejar al otro ser otro, dicho otro adquiere una gran positividad, no solo porque su existencia subsistente remonta a las generaciones del único Dios, en cuanto Padre, Hijo y Espíritu Santo, como suele insistir Balthasar, citando a Buenaventura, sino que la dualidad se constituye en aquel ritmo de la razón que es también el más propio del amor en su desborde de fecundidad y riqueza inaudita, es decir, en su estructura profundamente triádica.

La solución balthasareana del Problema Razón y Amor se gesta desde Dios Trino y Uno, en semejanza con mayor desemejanza; en permanente diálogo con aquellos filósofos, que aportan una mayor intelección a la estructura triádica del ser, aunque a modo de controversia como sucede con el interminable contrapunto del teólogo suizo con Hegel y Kant. Le parece grave a Balthasar el hecho de haber racionalizado el amor al extremo, poniéndolo al servicio de la "propia astucia de la razón”, y dejando al amor con el débil distintivo de una mera "sensación”. Igualmente grave le resulta el haber desconectado la razón del ser, como llevó a cabo Kant, y al cual ya Hegel quería poner remedio, cayendo, sin embargo, en el extremo opuesto al identificar el ser con la razón. Las extensas controversias balthasarianas con "los dialógicos", en apariencia más pacíficas que las señaladas con el idealismo alemán, pero más demoledoras todavía, logran, sin embargo, afinar la originalidad de la solución del teólogo suizo al Problema Razón y Amor.

En efecto, la razón es comprendida por Balthasar, en un primer momento, a la luz del vocablo latino ratio y su campo semántico; en un segundo paso, se remonta al vocablo griego $\log o s$ y, finalmente, se amplía plenamente hacia el conocimiento y sus diversificaciones semánticas. Esta sucesiva complementación articula un contenido conceptual de racionalidad cada vez más complejo, que parte de su precisión científica, lograda por Kant a través de la distinción entre Verstand (entendimiento) y Vernunft (razón), y la consecuente pérdida del nexo óntico con la realidad (el ser). El uso del logos, por su parte, recobra la profundidad griega que confluye con la articulación bíblica, lo cual permite la integración de la dimensión personal, concreta; sin embargo, el logos se expone al estrechamiento propio de la Lógica, tal como ella encuentra su expresión majestuosa en Hegel, en la identificación entre racionalidad y ser. El conocimiento, por fin, integra los componentes anteriores, sobrepasándolos por su índole procesal; gracias a los trascendentales, logra rescatar la ligazón congénita entre razón y ser, que, como tal, se abre connaturalmente al amor.

Según Balthasar, sin admitir contradicción, la razón articula "su" lógica natural. Sin embargo, a través de la contradicción de la vida (Blondel) y la "astucia de la razón" (Hegel), emerge una ruptura que convierte la negatividad de la muerte en positividad de vida. Como este devenir lo atestigua también la vida concreta del Logos encarnado, se da un enganche entre logicidad y ser a partir de una semejanza con mayor desemejanza, en la medida en que aquel se gesta a partir de la misma polaridad riqueza/pobreza. En efecto, la interpretación del actus essendi de Tomás por G. Siewerth pone de manifiesto dicha polaridad en su articulación de "amor extremo" jóanico. Esta extrema pobreza del ser, que se tornó riqueza a través de los entes, como lo explica la visión kenótica de F. Ulrich, se patentiza aquí en la contradicción del pecado, en cuanto misterio de iniquidad y que como tal se deduce de la misma vida intratrinitaria del Dios Amor. Así lo patentizan no solo las genera- 
ciones en Dios, tal como las explica Tomás, sino los trascedentales mismos que Buenaventura descubre en dichas generaciones. De tal modo, el Amor puede ser comprendido por Balthasar como el trascendental por excelencia, lo cual permite apreciar que la perijoresis congénita de Razón y Amor está mediada por el ser en calidad de "sentido" soteriológico último.

La razón alcanza su articulación plena en este tipo de "conocimiento" que equilibra los diversos elementos constituyentes de la racionalidad, en la medida en que los articula como relaciones totales en un punto medio, tal como lo indica la "expressio" del Hijo con respecto al Padre, y la Ein-sicht, el Verstand-nis que produce el Espíritu de ambos. Aquí confluyen los factores subjetivos y objetivos en la totalidad de un alguien de contornos particulares concretos, fruto y testimonio del amor mutuo, tal como lo atestigua el hijo a nivel creatural, y el Espíritu Santo en Dios. Es decir, el Padre y el Hijo a la vez, en una subistencia inefable en cuanto sempiterno "más", desde el cual el Infinito se explica conociéndose. El amor, pues, "se conoce" cada vez de nuevo, de modo finito en la infinitud, en la perijoresis viva de razón y amor. Aquí radica, en definitiva, la originalidad del aporte balthasariano al problema Razón y Amor.

\title{
RESUMEN
}

La antiquísima pregunta por la relación entre Razón y Amor recibe una respuesta novedosa en la obra de Hans Urs von Balthasar, en cuanto "lógica del amor". El presente estudio pretende verificarlo por medio de una lectura analítica de la Teológica, prestando atención especial a aquellos momentos cruciales, donde la razón humana se encuentra con su propio dilema: o contentarse consigo misma, o trascender hasta la infinitud, que la anticipa. Entonces, se trata de dilucidar la cuestión: ¿cuál es la función del amor en aquellos ejes de la argumentación balthasariana, que propone traducir la Lógica de Dios en la lógica humana?, mediante un método de indagación sencillo, que pretende detectar el enganche preciso de la racionalidad con el amor, tomando como punto de partida la base estadística exhaustiva de las veces en que el autor se refiere-explícita e implícitamente- a la ratio y su campo semántico.

\begin{abstract}
Hans Urs von Balthasar deals, in a novel way, with the long-standing question on the relation between Reason and Love, regarding it as a "logic of love". This article attempts to verify his proposal through an analytic reading of the Theologica. Special attention is paid to the crucial sections in which the Human Reason is faced with its dilemma: either self-indulge on one's own or transcend to the infinite. This article endeavours to answer the question: what is the function of love in the core of the Balthasarian argumentation, who attempts to decode the Divine logic into the human logic? The method of investigation attempts to identify the intersections which bring together rationality and love. The research starts from the comprehensive statistical basis of the number of times the author makes reference -explicitly or implicitly - to the ratio and to its semantic field.
\end{abstract}

